Carbon-13 Isotopic Abundance and Concentration of Atmospheric Methane for Background Air in the Southern and Northern Hemispheres From 1978 to 1989
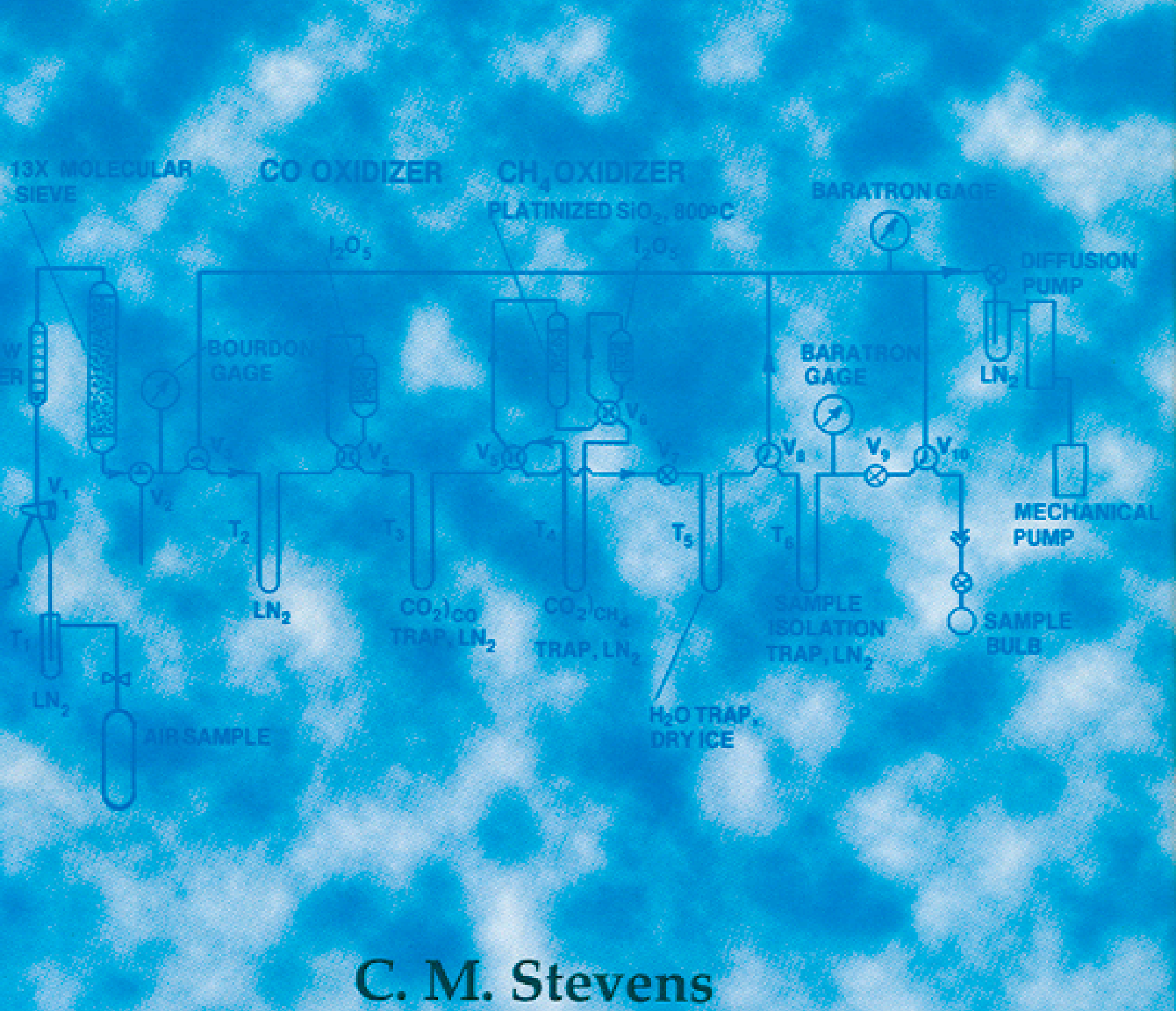

Chemical Technology Division Argonne National Laboratory

Argonne, Illinois 
This report has been reproduced directly from the best available copy.

Available to DOE and DOE contractors from the Office of Scientific and Technical Information, P.O. Box 62, Oak Ridge, TN 37831; prices available from (615) 576-8401, FTS 626-8401.

Available to the public from the National Technical Information Service, U.S. Department of Commerce, 5285 Port Royal Rd., Springfield, VA 22161.

This report was prepared as an account of work sponsored by an agency of the United States Government. Neither the United States Government nor any agency thereof, nor any of their employees, makes any warranty, express or implied, or assumes any legal liability or responsibility for the accuracy, completeness, or usefulness of any information, apparatus, product, or process disclosed, or represents that its use would not infringe privately owned rights. Reference herein to any specific commercial product, process, or service by trade name, trademark, manufacturer, or otherwise, does not necessarily constitute or imply its endorsement, recommendation, or favoring by the United States Government or any agency thereof. The views and opinions of authors expressed herein do not necessarily state or reflect those of the United States Government or any agency thereof. 


\section{DISCLAIMER}

Portions of this document may be illegible in electronic image products. Images are produced from the best available original document. 
ORNL/CDIAC-80

NDP-049

\title{
CARBON-13 ISOTOPIC ABUNDANCE AND CONCENTRATION OF ATMOSPHERIC METHANE FOR BACKGROUND AIR IN THE SOUTHERN AND NORTHERN HEMISPHERES FROM 1978 TO 1989
}

\author{
C. M. Stevens ${ }^{\dagger}$ \\ Chemical Technology Division \\ Argonne National Laboratory \\ Argonne, Illinois \\ Prepared by: \\ Robert J. Sepanski* \\ Laura J. Morris \\ - Energy, Environment, and Resources Center \\ The University of Tennessee \\ Knoxville, Tennessee \\ Environmental Sciences Division \\ Publication No. 4388 \\ Date Published: March 1995 \\ Prepared for the \\ Global Change Research Program \\ Environmental Sciences Division \\ Office of Health and Environmental Research \\ U.S. Department of Energy \\ (KP 0502000 ) \\ Prepared by the \\ Carbon Dioxide Information Analysis Center \\ OAK RIDGE NATIONAL LABORATORY \\ Oak Ridge, Tennessee 37831-6335 \\ managed by \\ MARTIN MARIETTA ENERGY SYSTEMS, INC. \\ for the \\ U.S. DEPARTMENT OF ENERGY \\ under contract DE-AC05-84OR21400
}

tWork supported by the U.S. Department of Energy under contract W-31-109-ENG-38 


\section{CONTENTS}

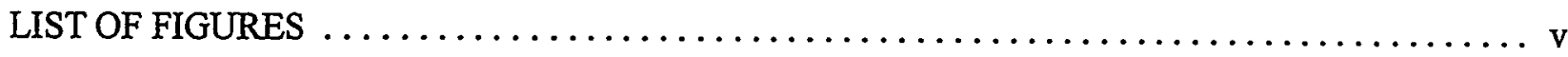

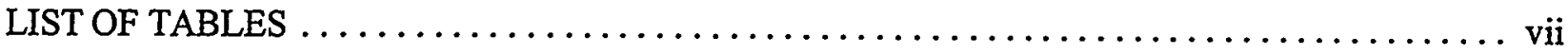

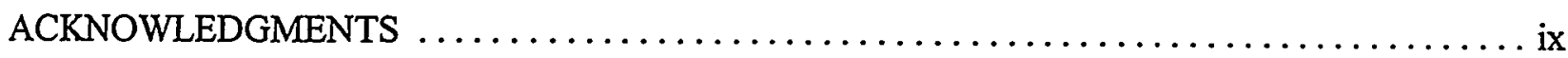

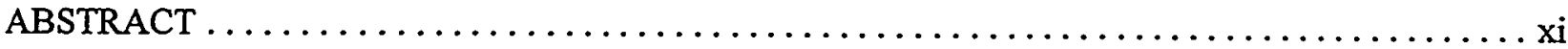

\section{PART I: OVERVIEW}

1. BACKGROUND AND SOURCE INFORMATION $\ldots \ldots \ldots \ldots \ldots \ldots \ldots \ldots \ldots \ldots$

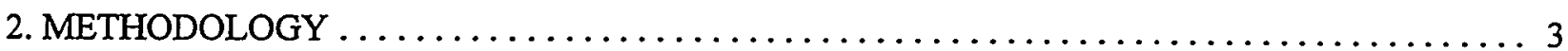

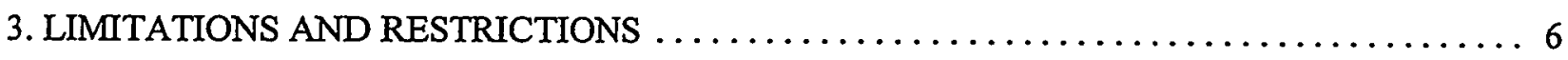

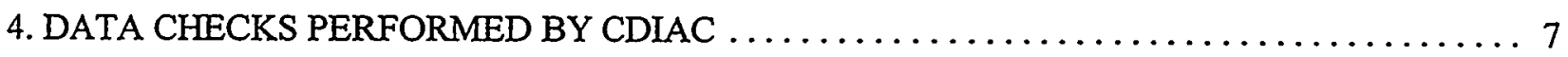

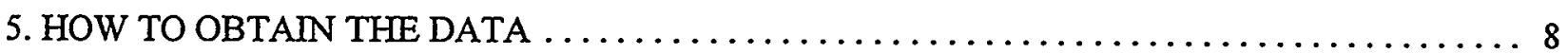

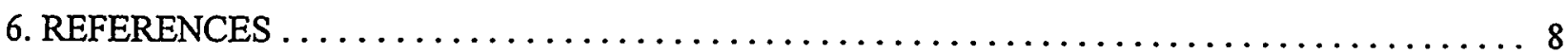

\section{PART II. CONTENT AND FORMAT OF DATA FILES}

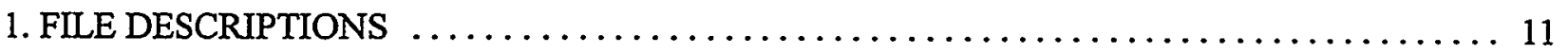

"ndp049.des" (descriptive file that complements the written documentation and provides details about the data files provided on the floppy diskette or other transfer medium).

"ndp049.dat" (atmospheric methane concentrations and carbon-13 isotopic abundances at globally distributed sites from 1978 through 1989)

"ndp049.for" (FORTRAN 77 data retrieval program to read and write the atmospheric methane concentration and carbon- 13 isotopic abundance data) 
"ndp049.sas" (SAS ${ }^{\circledast}$ data retrieval program to read and write the atmospheric methane concentration and carbon- 13 isotopic abundance data)

APPENDIX A. Carbon-13 Isotopic Abundance and Concentration of Atmospheric

Methane. ...............................

APPENDIX B. Reprint of Pertinent Literature $\ldots \ldots \ldots \ldots \ldots \ldots \ldots \ldots \ldots \ldots \ldots \ldots \ldots \ldots$ B-1

Isotopic abundances in the atmosphere and sources, by C.M. Stevens.

1993. 


\section{LIST OF FIGURES}

Figure

$\underline{\text { Page }}$

1. Schematic outline of gas train system for oxidizing $\mathrm{CH}_{4}$ in air samples to $\mathrm{CO}_{2}$ and

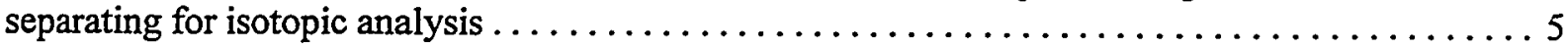




\section{LIST OF TABLES}

Table

Page

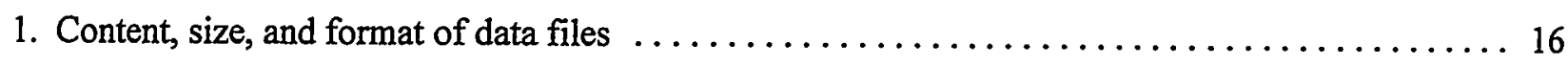




\section{.}




\section{ACKNOWLEDGMENTS}

Measurements were carried out in the Chemistry Division, Argonne National Laboratory, Argonne, II and supported by the Office of Basic Energy Sciences, Division of Mathematical and Geosciences, U.S. Department of Energy, Contract W-31-109-Eng-38 and the Interdisciplinary Research Program in Earth Sciences, National Aeronautics and Space Administration, Order No. W-16188. 



\section{ABSTRACT}

Stevens, C.M. 1995. Carbon-13 Isotopic Abundance and Concentration of Atmospheric Methane for Background Air in the Southern and Northern Hemispheres from 1978 to 1989. ORNL/CDIAC-80, NDP-049. Carbon Dioxide Information Analysis Center, Oak Ridge National Laboratory, Oak Ridge, Tennessee, U.S.A. 60 pp. doi: 10.3334/CDIAC/atg.ndp049

This document presents atmospheric $\mathrm{CH}_{4}$ concentration and carbon-13 isotopic abundance data derived from air samples collected over the period 1978-1989 at globally distributed clean-air sites. The data set comprises 201 records, 166 from the Northern Hemisphere and 35 from the Southern Hemisphere. The air samples were collected mostly in remote rural or marine locations, far from large sources of $\mathrm{CH}_{4}$, and are considered representative of tropospheric background conditions. The air samples were processed by isolation of $\mathrm{CH}_{4}$ from air and conversion to $\mathrm{CO}_{2}$ for isotopic analysis by isotope-ratio mass spectrometry. These data represent one of the earliest records of carbon-13 isotopic data for atmospheric methane and have been used to refine estimates of $\mathrm{CH}_{4}$ emissions, calculate annual growth rates of emissions from changing sources, and provide evidence for changes in the rate of atmospheric removal of $\mathrm{CH}_{4}$.

The data records consist of sample collection date; number of samples combined for analysis; sampling location; analysis date; $\mathrm{CH}_{4}$ concentration; carbon-13 isotopic abundance; and flag codes to indicate data outliers, repeated analyses, and other information. The data are available free of charge as a numeric data package (NDP) from the Carbon Dioxide Information Analysis Center. The NDP consists of this document and a floppy diskette (or other medium, upon request) containing machine-readable files. This document provides a complete listing of the atmospheric $\mathrm{CH}_{4}$ concentration and carbon-13 isotopic abundance data. This document also contains retrieval program listings (in FORTRAN and $\mathrm{SAS}^{\circledR}$ languages), furnishes information on analysis methods, defines limitations and restrictions of the data, and provides a reprint of a pertinent paper from the literature.

Keywords: air samples, atmospheric methane, carbon-13, global distribution, isotope, mass spectrometry, trends 
PART I OVERVIEW 



\section{BACKGROUND AND SOURCE INFORMATION}

Atmospheric methane $\left(\mathrm{CH}_{4}\right)$ may become an increasingly important contributor to global warming in future years. Its atmospheric concentration has risen, doubling over the past several hundred years, and additional methane is thought to have a much greater effect on climate, on a per molecule basis, than additional $\mathrm{CO}_{2}$ at present day concentrations (Shine et al. 1990). The causes of the increase of atmospheric $\mathrm{CH}_{4}$ have been difficult to ascertain because of a lack of quantitative knowledge of the fluxes (i.e., net emissions) from the numerous anthropogenic and natural sources. The goal of $\mathrm{CH}_{4}$ isotopic studies is to provide a constraint (and so reduce the uncertainties) in estimating the relative fluxes from the various isotopically distinct sources, whose combined fluxes must result in the measured atmospheric isotopic composition, after the fractionating effect of the atmospheric removal process is considered. In addition, knowledge of the spatial and temporal changes in the isotopic composition of atmospheric $\mathrm{CH}_{4}$, along with estimates of the fluxes from some of the major sources, makes it possible to calculate growth rates for sources whose temporal emissions trends would be difficult to measure directly. A detailed discussion of the use of carbon isotopic data to elucidate $\mathrm{CH}_{4}$ source fluxes and growth rates is given in Stevens (1993), a reprint of which is included as Appendix B.

The atmospheric $\mathrm{CH}_{4}$ concentration and carbon-13 isotopic abundance data presented in this package are derived from air samples collected over the period 1978-1989 at globally distributed clean-air sites. The data set (presented in its entirety in hard copy form as Appendix A) comprises 201 records, 166 from the Northern Hemisphere and 35 from the Southern Hemisphere. The air samples were collected mostly in remote rural or marine locations, far from large sources of $\mathrm{CH}_{4}$, and are considered representative of tropospheric background conditions. Sampling locations in the Northern Hemisphere included 32 Pacific Ocean sites and 11 land-based sites. In the Southern Hemisphere, locations included 18 Pacific Ocean sites and 4 land-based sites. At many locations, air samples were collected by C.M. Stevens and his colleagues. For some Southern Hemisphere and Pacific Ocean measurements, and all measurements at Cape Meares, Oregon, samples were obtained from stored air cylinders contributed by R.A. Rasmussen from the sample bank at the Oregon Graduate Institute of Science and Technology (formerly the Oregon Graduate Center), Portland, Oregon, U.S.A.

These data represent one of the earliest records of carbon-13 isotopic measurements for atmospheric methane at globally distributed clean-air sites. Additional information, including measurements of the isotopic composition of $\mathrm{CH}_{4}$ sources, estimates of the atmospheric lifetime of $\mathrm{CH}_{4}$, measurements of carbon-14 abundances in atmospheric $\mathrm{CH}_{4}$, and some $\mathrm{CH}_{4}$ source flux estimates derived from emissions inventories, are provided in Stevens (1993). Together with these additional data, the atmospheric ${ }^{13} \mathrm{CH}_{4}$ data presented in this package have been used to refine estimates of the global $\mathrm{CH}_{4}$ fluxes from combined rice and cattle production and from biomass burning, to calculate growth rates in $\mathrm{CH}_{4}$ fluxes

from biomass burning in the Southern Hemisphere and from natural wetlands in the Northern

Hemisphere, and to provide evidence of changes in the rate of the atmospheric removal process (Stevens, 1993).

\section{METHODOLOGY}

Sampling Techniques and Conditions

The sampling in both hemispheres occurred in two main phases: 
Phase 1: Samples collected during 1978-83 were, with few exceptions, obtained from the air sample bank of the Oregon Graduate Center in collaboration with R.A. Rasmussen. The samples in the bank had been stored from 1 to 5 years in cleaned and treated stainless steel cylinders of various sizes (approximately 2 to 30 liters) and at various high pressures (up to 25 atmospheres). These cylinders were shipped to Argonne National Laboratory and then transferred by expansion to atmospheric pressure into 33-liter evacuated stainless steel cylinders (untreated WWII-surplus oxygen cylinders) of accurately known volume and analyzed within 1 to 2 days. The air in these stored samples had been collected either at sea or at land stations upwind of any urban or anthropogenic sources of $\mathrm{CH}_{4}$. During this period, some of the Northern Hemisphere samples were collected at the Cape Meares station of the Oregon Graduate Center; the others were taken at sea in the Pacific. Beginning in 1983, samples were also collected in Northern Illinois. The average $\delta^{13} \mathrm{C}$ values of 36 samples collected in Northern Illinois during 1983 were compared with the average of seven samples collected at Cape Meares during the same year and were found to agree within 0.01 per mil.

Phase 2: From 1984 through 1989 all samples were collected in Argonne 33-liter evacuated stainless steel cylinders (untreated WWII-surplus oxygen cylinders), either at rural sites in Northern Illinois or, in the case of the Southern Hemisphere samples, at rural sites upwind of Canberra (Australia), or at the shore near the NOAA observatory in American Samoa. A special set of analyses was carried out in 1988 on four samples which had been collected in 1978 and analyzed in 1983, in order to compare results after another five years of storage. The results of these reanalyses are found in the data set (see data for samples collected at Cape Meares, dated 4-4-78, 4-7-78, 10-5-78, and 10-5-78).

The Illinois samples were collected mostly in the afternoon on days with winds in excess of $10 \mathrm{mph}$. Collections in the morning were avoided because of overnight temperature inversions. Typically, only one flask sample was collected at each site. An exception occurred on 9-8-88, when six different samples in six different flasks were collected simultaneously and analyzed at intervals over a six week period in order to ascertain the integrity of samples stored in Argonne cylinders. Multiple samples were combined only when it was necessary to combine air stored in several small cylinders (obtained from the Oregon Graduate Institute) in order to make enough for the 33 liters required for isotopic analysis. Multiple analyses from a single flask occurred in several cases, as in the samples with collection times denoted 11-00-81 (Tasmania) and 05-00-82 (Pacific). (Days denoted as 00, as in 11-00-81, indicate that the exact day of sampling is not known.)

\section{Analytical Methods}

Air samples were processed by the oxidation of the $\mathrm{CH}_{4}$ in the air to $\mathrm{CO}_{2}$ after quantitative removal of atmospheric $\mathrm{CO}_{2}$ and $\mathrm{CO}_{2}$ from oxidation of atmospheric $\mathrm{CO}$ by Schutze reagent. (The experimental apparatus used to carry out this procedure is shown schematically in Figure 1.) The $\mathrm{CO}_{2}$ from $\mathrm{CH}_{4}$ oxidation was quantitatively separated from the air by distillation and analyzed isotopically. Details of the experimental procedures are as follows.

The air pressure in the sampling flask was first measured, then the flask was connected to the air intake line and air was passed through a low-efficiency, high-flow liquid $\mathrm{N}_{2}$ trap to remove water, most of the atmospheric $\mathrm{CO}_{2}$, and non-methane hydrocarbons. Next, the samples were passed through molecular sieve $13 \mathrm{X}$ and another liquid $\mathrm{N}_{2}$ trap of high efficiency to further remove any $\mathrm{CO}_{2}$ present. The air stream was then passed through a granular Schutze reagent made up of $\mathrm{I}_{2} \mathrm{O}_{5}$ on silica gel, by which the atmospheric $\mathrm{CO}$ was oxidized to $\mathrm{CO}_{2}$. Another liquid $\mathrm{N}_{2}$ trap then removed this $\mathrm{CO}_{2}$. The gas was then passed through an electrically heated quartz combustion tube containing platinized silica, which quantitatively oxidizes the $\mathrm{CH}_{4}$ to $\mathrm{CO}_{2}$ and $\mathrm{H}_{2} \mathrm{O}$, which are then trapped in high-efficiency, liquid $\mathrm{N}_{2}$ 


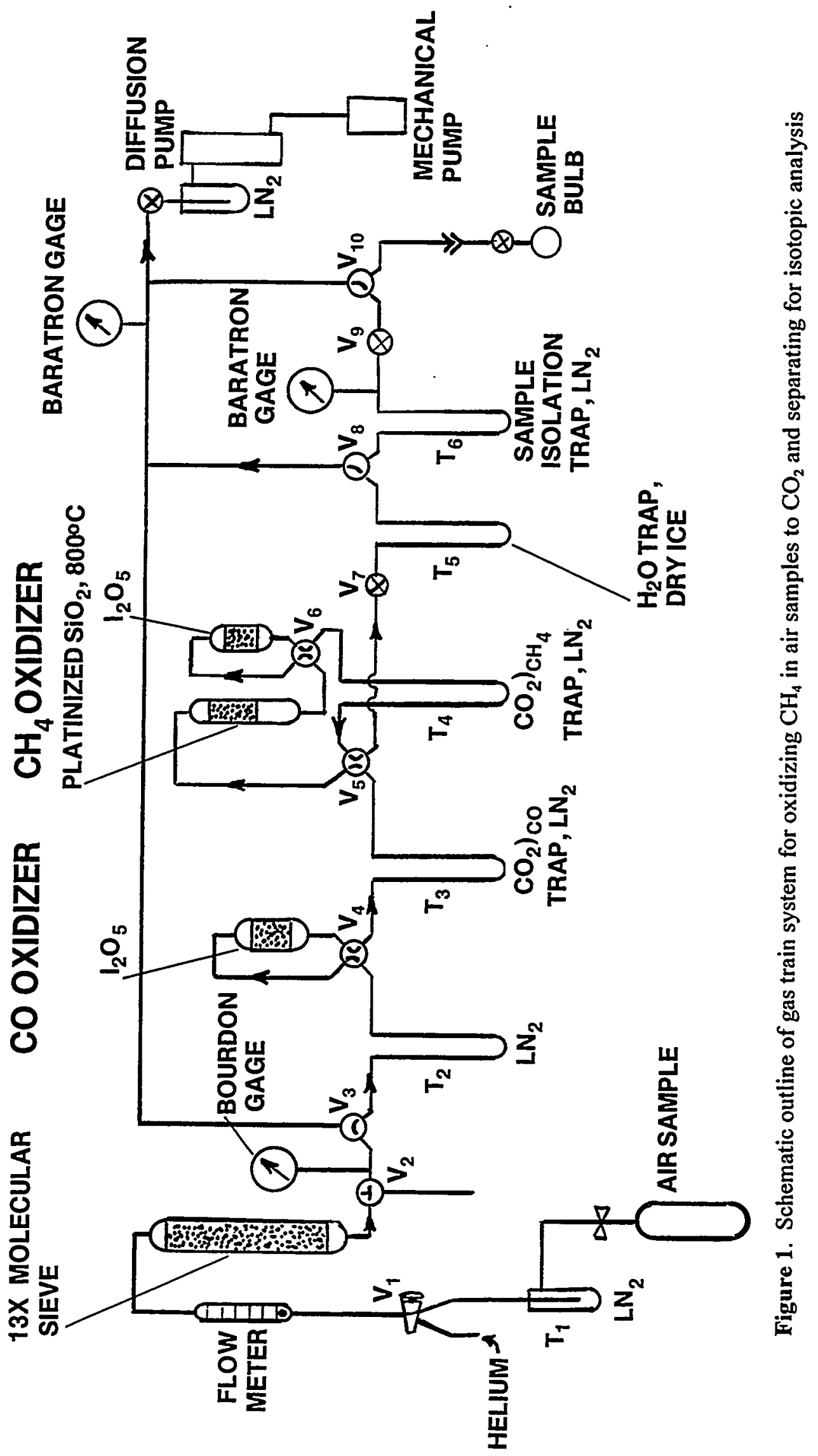


traps. The air in the original cylinder was passed through this treatment until the pressure was reduced to approximately $5 \%$ of atmospheric pressure. The flow rate was maintained at a constant flow of approximately 0.5 liters/min by adjustment of the valve on the cylinder until the valve was wide open and the pressure was reduced to approximately $25 \%$ of atmospheric pressure; the flow then gradually decreases until terminated at $5 \%$ of atmospheric pressure. The line beyond the $\mathrm{CH}_{4}$ combustion section was pumped to a good vacuum and then isolated. The trap with the $\mathrm{CO}_{2}$ and $\mathrm{H}_{2} \mathrm{O}$ from $\mathrm{CH}_{4}$ oxidation was warmed with a hot water bath, and the $\mathrm{CO}_{2}$ and $\mathrm{H}_{2} \mathrm{O}$ were transferred with a controlled helium flow through a trap cooled by dry ice/methanol to remove the $\mathrm{H}_{2} \mathrm{O}$. The $\mathrm{CO}_{2}$ was condensed in a trap in the micromanometer section, which was then pumped to a good vacuum and isolated. The trap containing the $\mathrm{CO}_{2}$ from $\mathrm{CH}_{4}$ oxidation was then warmed, and the $\mathrm{CO}_{2}$ pressure was measured with a precision of $\pm 0.3 \%$. Finally, the $\mathrm{CO}_{2}$ was distilled to a sample tube for isotopic analysis on a Consolidated-Nier isotope-ratio mass spectrometer. The concentration of $\mathrm{CH}_{4}$ was calculated stoichiometrically with a precision of $\pm 0.5 \%$. The $\delta^{13} \mathrm{C}$ values of the $\mathrm{CO}_{2}$ samples were measured with a precision of \pm 0.05 per mil. A correction of -0.11 per mil was made for an impurity of $\mathrm{N}_{2} \mathrm{O}$ produced in the combustion train. The overall uncertainties in the analyzed values of $\mathrm{CH}_{4}$ concentration and isotopic composition are estimated to be 0.02 parts per million (ppm) for the concentration values, 0.2 per mil for isotopic values prior to 1985 , and 0.1 per mil for isotopic values after 1985 .

\section{LIMITATIONS AND RESTRICTIONS}

The isotopic results for the samples of stored air from 1978 through 1983 were all analyzed during $1982-83$ in random order and using a laboratory isotopic standard which had been accurately measured at -24.8 per mil. This standard had been used for many years and was replenished without fractionation 2-3 times per year. The order of processing and analysis of samples was random for both the hemisphere of origin and the chronology of collection; therefore, it is unlikely that there are any systematic errors in the set of samples from this period. The same cannot be said for the samples from 1984 through 1989. During this period, new isotopic working standards were started, having a value nearly the same as the isotopic composition of the $\mathrm{CH}_{4}$ samples in order to reduce the mass spectrometer error resulting from measuring large differences, sometimes called the "memory" effect. There may have been some drift of the value of the isotopic standard due to fractionation while it was consumed during the analysis process, as these standards were not prepared in large amounts as had been the case for the standard used for the earlier samples. The repeat analyses done in 1988 on second aliquots of four of the stored air samples showed an average difference of +0.3 per mil compared to the first analysis done five years earlier using the -24.8 per mil isotopic standard. This difference is attributed to background $\mathrm{CH}_{4}$ contamination from the cylinder during storage. The analyses of all stored air samples were therefore corrected by -0.067 per mil per year of storage time between the collection and analysis dates (see column 9 of the data set, included as Appendix A). Another check of the last isotopic standard used for the 1988-89 samples indicated a possible drift of about +0.5 per mil.

The most important feature of the isotopic data is the measured interhemispheric trend, which is independent of the individual hemispheric trends because the analyses were done with the same standard at more or less the same time period. Mathematical analysis of the hemispheric trends shows that the difference of the hemispheric trends is the most important term in the calculation of the trends of the fluxes in each hemisphere. The average trend of each hemisphere is of secondary importance in the analysis. Hence, systematic errors such as fractionation of the isotopic standard would have only a small effect on the final application of the results. 
Additional uncertainties may affect the ability to compare isotopic ratios in atmospheric $\mathrm{CH}_{4}$ from clean-air sites with isotopic ratios from the various source types for the purpose of resolving uncertainties in the global methane budget. Perhaps the largest uncertainty is the determination by inventory estimates of the globally averaged isotopic ratio of individual sources such as biomass burning or methane from ruminants. This uncertainty arises because the $\mathrm{CH}_{4}$ from these sources is made up of contributions of uncertain relative amounts globally from metabolically distinct plant types (i.e., $\mathrm{C}_{3}$ and $\mathrm{C}_{4}$ plants), which have large isotopic variations. The globally averaged isotopic composition of $\mathrm{CH}_{4}$ sources from coal mining and natural gas losses are subject to large uncertainties of $\pm 4 \%$ because of large variations among the many individual sources.

\section{DATA CHECKS PERFORMED BY CDIAC}

The Carbon Dioxide Information Analysis Center (CDIAC) endeavors to provide quality assurance (QA) of all data before their distribution. To ensure the highest possible quality in the data, CDIAC conducts extensive reviews for reasonableness, accuracy, completeness, and consistency of form. While having common objectives, the specific form of these reviews must be tailored to each data set; this tailoring process may involve considerable programming efforts. The entire QA process is an important part of CDIAC's effort to assure accurate, usable data for researchers.

For the atmospheric methane concentration and carbon-13 isotopic abundance data, the QA procedure consisted of the following:

1. The format of all information was checked to ensure consistency throughout each data record.

2. Data values were examined for reasonableness, absence of typographical errors, and absence of outliers.

No errors or inconsistencies of the types described above were found in the atmospheric methane concentration and carbon- 13 isotopic abundance data received by CDIAC. All data values in the file distributed by CDIAC are identical to those received from C.M. Stevens. However, in order to enhance their value and their ease of use, the data records were reformatted and appended in the following way:

1. The latitude and longitude of each sampling site, which were absent for most locations in the original data set, were obtained from C.M. Stevens and appended to each data record.

2. The conventions for missing values and repeated analyses were altered in order to create a consistent format for all data records. New flag codes were created to identify any of the following: (1) uncertainties in the analysis date, (2) records that represent repeated measurements, and (3) records that represent averages of two or more previous measurements. 


\section{HOW TO OBTAIN THE DATA}

This documentation and the data described herein are available from:

$$
\begin{gathered}
\text { Carbon Dioxide Information Analysis Center } \\
\text { Oak Ridge National Laboratory } \\
\text { Post Office Box } 2008 \\
\text { Oak Ridge, TN } 37831-6335 \text {, U.S.A. } \\
\text { Telephone (615) } 574-3645 \text { or (615) 241-4851 }
\end{gathered}
$$

The following citation should be used for referencing this archive and/or this documentation report:

Stevens, C.M. 1995. Carbon-13 Isotopic Abundance and Concentration of Atmospheric Methane for Background Air in the Southern and Northern Hemispheres from 1978 to 1989. ORNL/CDIAC-80, NDP-049. Carbon Dioxide Information Analysis Center, Oak Ridge National Laboratory, Oak Ridge, Tennessee, U.S.A.

\section{REFERENCES}

Rust, F., and C.M. Stevens. 1980. Carbon kinetic isotope effect in the oxidation of methane by hydroxyl. International Journal of Chemical Kinetics 12:371-77.

Shine, K.P., R.G. Derwent, D.J. Wuebbles, and J-J. Morcrette. 1990. Radiative forcing of climate. pp. 41-68. In J.T. Houghton, G.J. Jenkins, and J.J. Ephraums (eds.), Climate Change: the IPCC Scientific Assessment. Cambridge University Press, Cambridge.

Stevens, C.M. 1993. Isotopic abundances in the atmosphere and sources. pp. 62-88. In M.A.K. Khalil (ed), Atmospheric Methane: Sources, Sinks, and Role in Global Change. Proceedings of the NATO Advanced Research Workshop on the Atmospheric Methane Cycle: Sources, Sinks, Distributions, and Role in Global Change, held at Mt. Hood near Portland, OR, U.S.A., October 7-11, 1991. NATO ASI Series I: Global Environmental Change, Vol. 13. Springer-Verlag, Berlin and Heidelberg.

Stevens, C.M. 1988. Atmospheric methane. Chemical Geology 71:11-21.

Stevens, C.M., and A. Engelkemeir. 1988. Stable carbon isotopic composition of methane from some natural and anthropogenic sources. Journal of Geophysical Research 93(D1): 725-33.

Stevens, C.M., and A. Engelkemeir. 1985. Causes of increasing methane fluxes based on carbon isotopic studies. Special Environmental Report No. 16, WMO 647. WMO Technical Conference on Observation and Measurement of Atmospheric Contaminants. World Meteorological Organization, Geneva. 
PART II

CONTENT AND FORMAT OF DATA FILES 

-- 


\section{FILE DESCRIPTIONS}

Filename: ndp049.des

This file contains a detailed description of both the data set and the digital data file. It is intended to serve as a digital version of Sects. I-1-I-6 and II-1 of this printed document (figure excluded).

Filename: ndp049.dat

This $21.5 \mathrm{kB}$ file presents 201 records (166 records from Northern Hemisphere sites and 35 records from Southern Hemisphere sites) of atmospheric methane concentrations and carbon-13 isotopic abundances from background (clean-air) samples collected at globally distributed sites from 1978 through 1989.

Each data record presents the following variables: sample collection date; number of samples combined for analysis; sampling location (site name, latitude, and longitude); analysis date; $\mathrm{CH}_{4}$ concentration; carbon-13 isotopic abundance (uncorrected and corrected); and flag codes to indicate outliers, repeated analyses of a sample, and other information. The file can be read by using the following FORTRAN code:
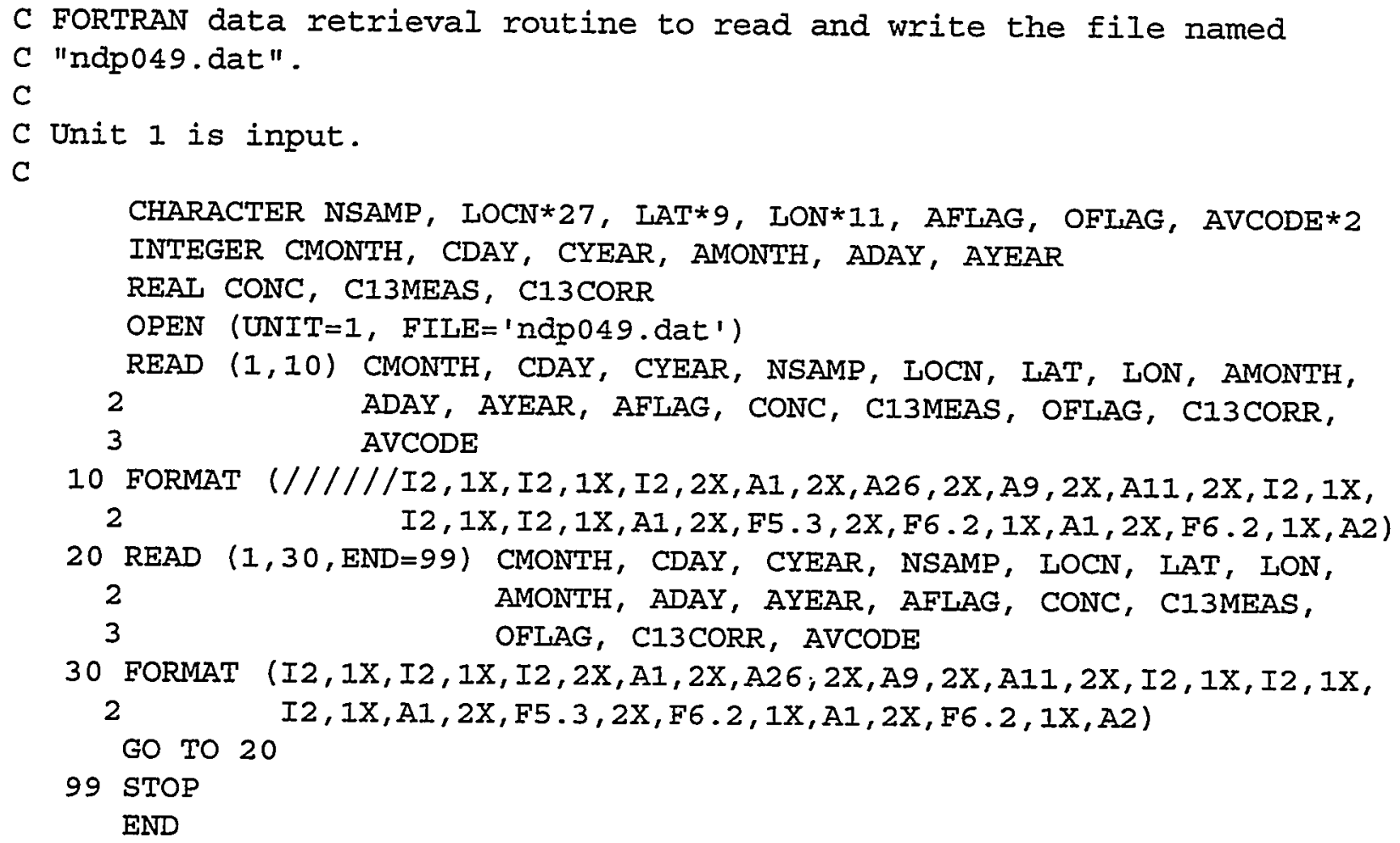

The data can also be read by using the following SAS ${ }^{\circledR}$ code:

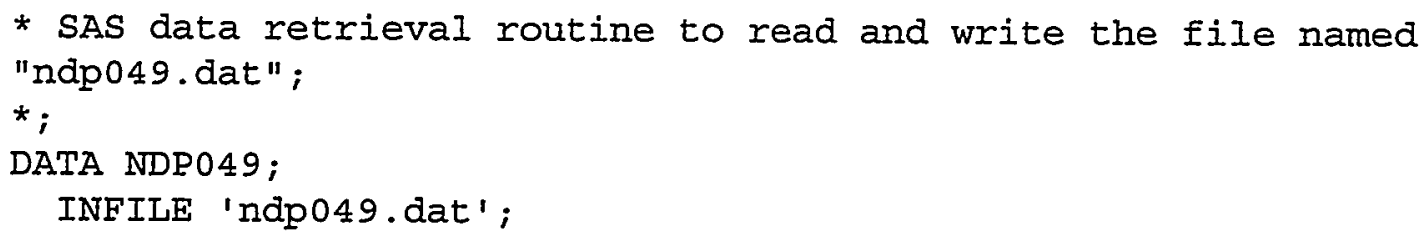




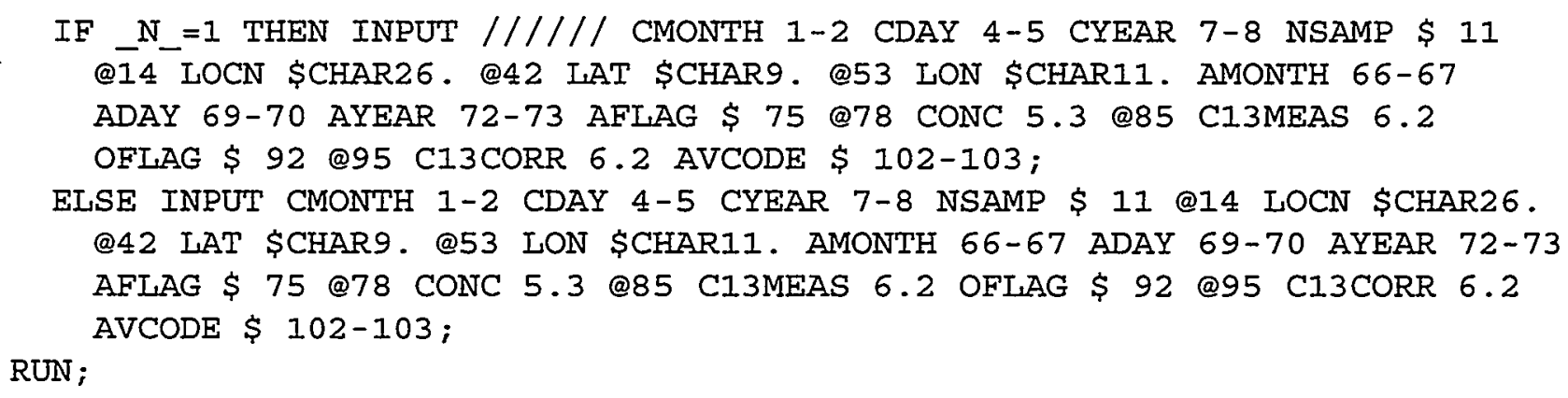

where

CMONTH is the numeric month of the year in which the air sample was collected;

CDAY is the numeric day of the month on which the air sample was collected;

CYEAR is the final two digits of the year (since 1900) in which the air sample was collected;

NSAMP is the number of samples combined from different locations for a single analysis;

LOCN is a descriptive character string consisting of (1) the location of the sampling site and, in some cases, (2) the sample number(s), denoted as one or more numbers following a "\#" sign and referring to the identity of the stored air sample(s) contributed from the sample bank at the Oregon Graduate Institute of Science and Technology, Portland, Oregon, U.S.A., by R.A. Rasmussen;

LAT is the estimated latitude (or range of latitudes) of the sampling site(s), given in decimal degrees;

LON is the estimated longitude (or range of longitudes) of the sampling site(s), given in decimal degrees;

AMONTH is the numeric month of the year in which the air sample was analyzed;

ADAY is the numeric day of the month on which the air sample was analyzed;

AYEAR is the final two digits of the year (since 1900) in which the sample was analyzed;

AFLAG is a one-character flag code providing additional information about the sample analysis: ' $R$ ' - entry represents one of two or more repeated analyses carried out on the same air sample; ' $\mathrm{C}$ '- identifies samples where the actual date of analysis is not given but was within one week of the date of collection;

CONC is the $\mathrm{CH}_{4}$ concentration in the air sample, given in parts per million $\left(1 \times 10^{6}\right)$ by volume;

C13MEAS is the measured $\delta^{13} \mathrm{C}$ (per mil), corrected by +0.10 per mil for $\mathrm{N}_{2} \mathrm{O}$ contamination but uncorrected for water vapor contamination; 
OFLAG is a one-character flag code denoting values of C13MEAS that are considered as outliers and not included in any subsequent averages; the symbol for the flag code is "*";

C13CORR is a corrected value of $\delta^{13} \mathrm{C}$ (per mil), calculated only for samples stored for a considerable time before analysis; values represent an addition of -0.067 per mil per year for background contamination (from the cylinder walls) that accumulated between the collection and analysis dates;

AVCODE is a two-character code denoting an entry whose C13CORR value is an average of those of the previous 2 to 5 entries [i.e., the immediately preceding entries containing AFLAG values of 'R' (excluding outliers, denoted by OFLAG $=" * * ")]: A 2, A 3$, and $A 5$ signify entries representing averages of 2,3 , and 5 previous entries, respectively.

Stated in tabular form, the contents include the following.

\begin{tabular}{llrcr}
\hline Variable & $\begin{array}{l}\text { Variable } \\
\text { type }\end{array}$ & $\begin{array}{c}\text { Variable } \\
\text { width** }\end{array}$ & $\begin{array}{c}\text { Starting } \\
\text { column }\end{array}$ & $\begin{array}{c}\text { Ending } \\
\text { column }\end{array}$ \\
\hline CMONTH & Numeric & I2 & 1 & 2 \\
CDAY & Numeric & I2 & 4 & 5 \\
CYEAR & Numeric & I2 & 7 & 8 \\
NSAMP & Character & A1 & 11 & 11 \\
LOCN & Character & A26 & 14 & 39 \\
LAT & Character & A9 & 42 & 50 \\
LON & Character & A11 & 53 & 63 \\
AMONTH & Numeric & I2 & 66 & 70 \\
ADAY & Numeric & I2 & 69 & 73 \\
AYEAR & Numeric & I2 & 72 & 75 \\
AFLAG & Character & A1 & 75 & 92 \\
CONC & Numeric & F5.3 & 78 & 90 \\
C13MEAS & Numeric & F6.2 & 85 & 100 \\
OFLAG & Character & A1 & 92 & 103 \\
C13CORR & Numeric & F6.2 & 95 & \\
AVCODE & Character & A2 & 102 &. \\
& & & &
\end{tabular}

- Missing values for numeric variables are represented as follows - CMONTH, CDAY, CYEAR, AMONTH, ADAY, AYEAR: 00; CONC: 9.999; C13MEAS, C13CORR: 999.99. Missing values for character variables (NSAMP, AFLAG, OFLAG, AVCODE) are represented as blanks.

"* Values for variable width are entered as FORTRAN 77 format codes. 
Filename: ndp049.for

This file contains a FORTRAN 77 data retrieval routine to read and write the file "ndp049.dat". The following is a listing of this program. For additional information regarding variable definitions and format statements, please see the file description for "ndp049.dat" on pages 11-13.

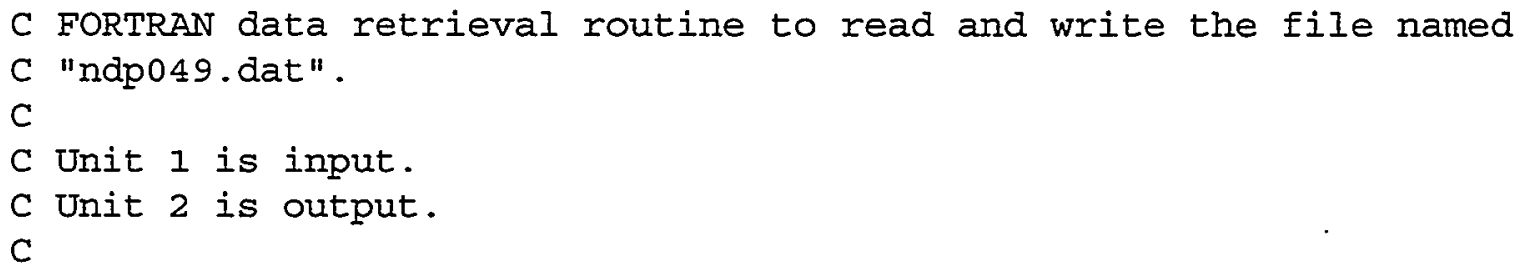


Filename: ndp049.sas

This file contains a SAS ${ }^{\circledR}$ data retrieval routine to read and write the file "ndp049.dat". The following is a listing of this program. For additional information regarding variable definitions and format statements, please see the file description for "ndp049.dat" on pages 11-13.

* SAS data retrieval routine to read the file named "ndp049.dat"; *;

DATA NDP049;

INFILE 'ndp049.dat';

IF _N_=1 THEN INPUT $/ / / / / /$ CMONTH \$ 1-2 CDAY \$ 4-5 CYEAR \$ 7-8 NSAMP \$ 11 @14 LOCN \$CHAR26. @42 LAT \$CHAR9. @53 LON \$CHAR11.

AMONTH \$ 66-67 ADAY \$ 69-70 AYEAR \$ 72-73 AFLAG \$ 75

@78 CONC 5.3 @85 C13MEAS 6.2 OFIAG \$ $92 @ 95$ C13CORR 6.2 AVCODE \$ 102-103;

ELSE INPUT CMONTH \$ 1-2 CDAY \$ 4-5 CYEAR \$ 7-8 NSAMP \$ 11 @14 LOCN \$CHAR26. @42 LAT \$CHAR9. @53 LON \$CHAR11.

AMONTH \$ 66-67 ADAY \$ 69-70 AYEAR \$ 72-73 AFLAG \$ 75

@78 CONC 5.3 @85 CI3MEAS 6.2 OFLAG \$92 @95 CI3CORR 6.2 AVCODE \$ 102-103;

FILE 'output';

PUT CMONTH 1-2 CDAY 4-5 CYEAR 7-8 NSAMP 11 @14 LOCN \$CHAR26. @42 LAT \$CHAR9. @53 LON \$CHAR11. AMONTH 66-67 ADAY 69-70 AYEAR 72-73 AFLAG 75 @78 CONC 5.3 @85 C13MEAS 6.2 OFLAG 92 RUN ; (995 C13CORR 6.2 AVCODE 102-103; 
Table 1. CONTENT, SIZE, and FORMAT of DATA FILES

\begin{tabular}{lcccc}
\hline $\begin{array}{l}\text { File number and } \\
\text { name }\end{array}$ & $\begin{array}{l}\text { Logical } \\
\text { records }\end{array}$ & $\begin{array}{l}\text { File } \\
\text { size in } \mathrm{kB}\end{array}$ & $\begin{array}{l}\text { Block } \\
\text { size }^{1}\end{array}$ & $\begin{array}{c}\text { Record } \\
\text { length }\end{array}$ \\
\hline & 555 & 45.0 & 8000 & 80 \\
1. ndp049.des & 31 & 2.5 & 8000 & 80 \\
2. ndp049.for & 18 & 1.5 & 8000 & 80 \\
3. ndp049.sas & 207 & 21.5 & 8000 & 103 \\
4. ndp049.dat & 811 & 70.5 & & \\
Total: & & & \\
\hline
\end{tabular}

${ }^{1}$ The block size pertains only to files on magnetic tape. 


\section{APPENDIX A.}

Carbon-13 Isotopic Abundance and Concentration of Atmospheric Methane 



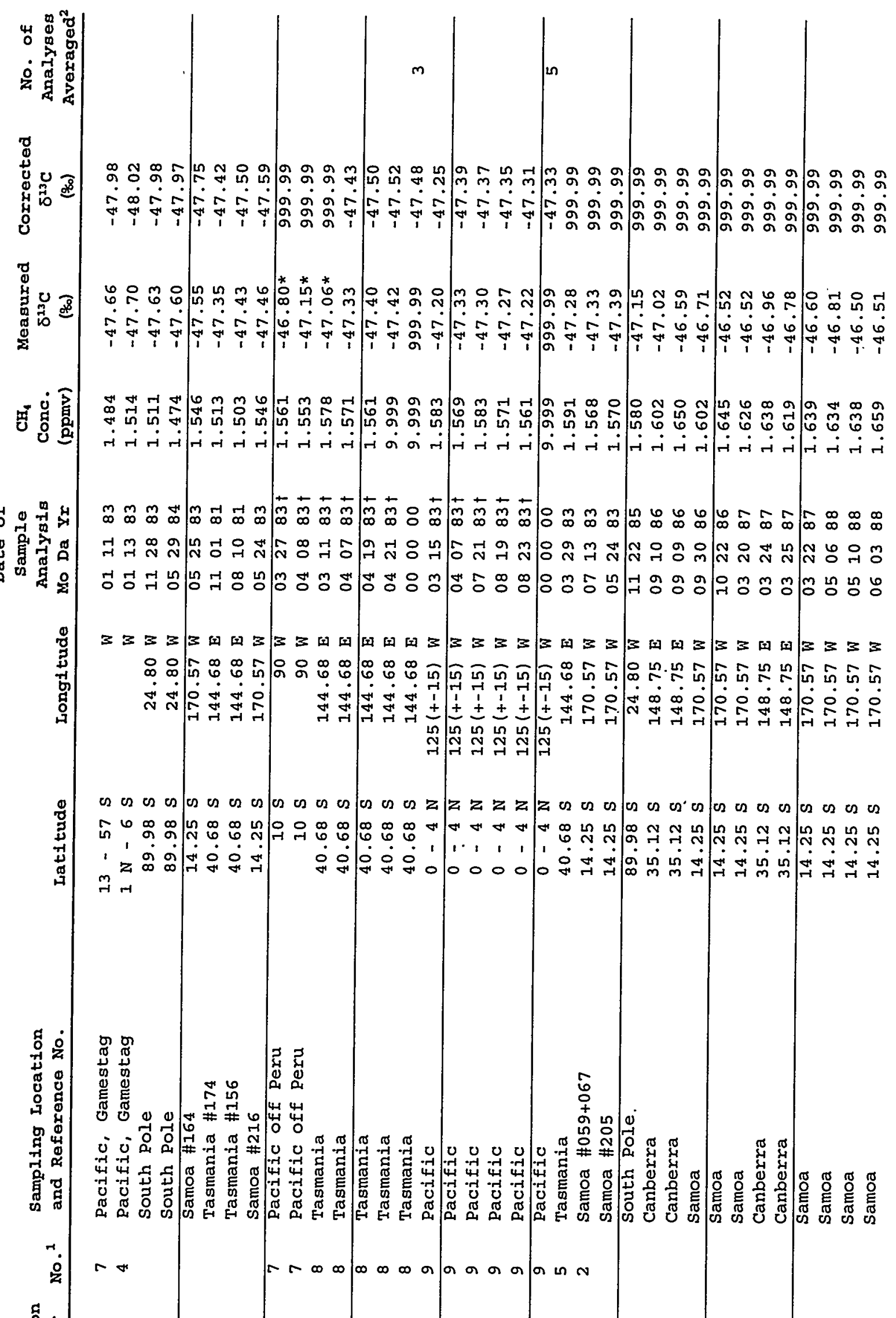

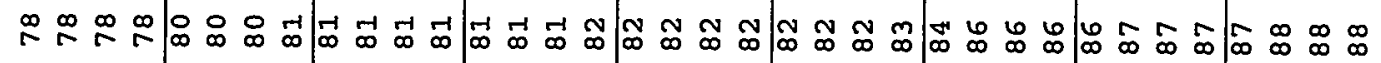

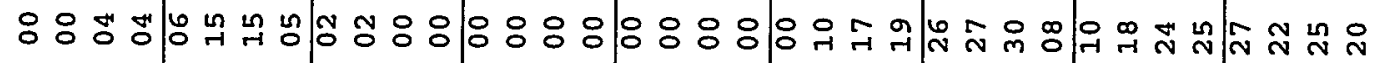




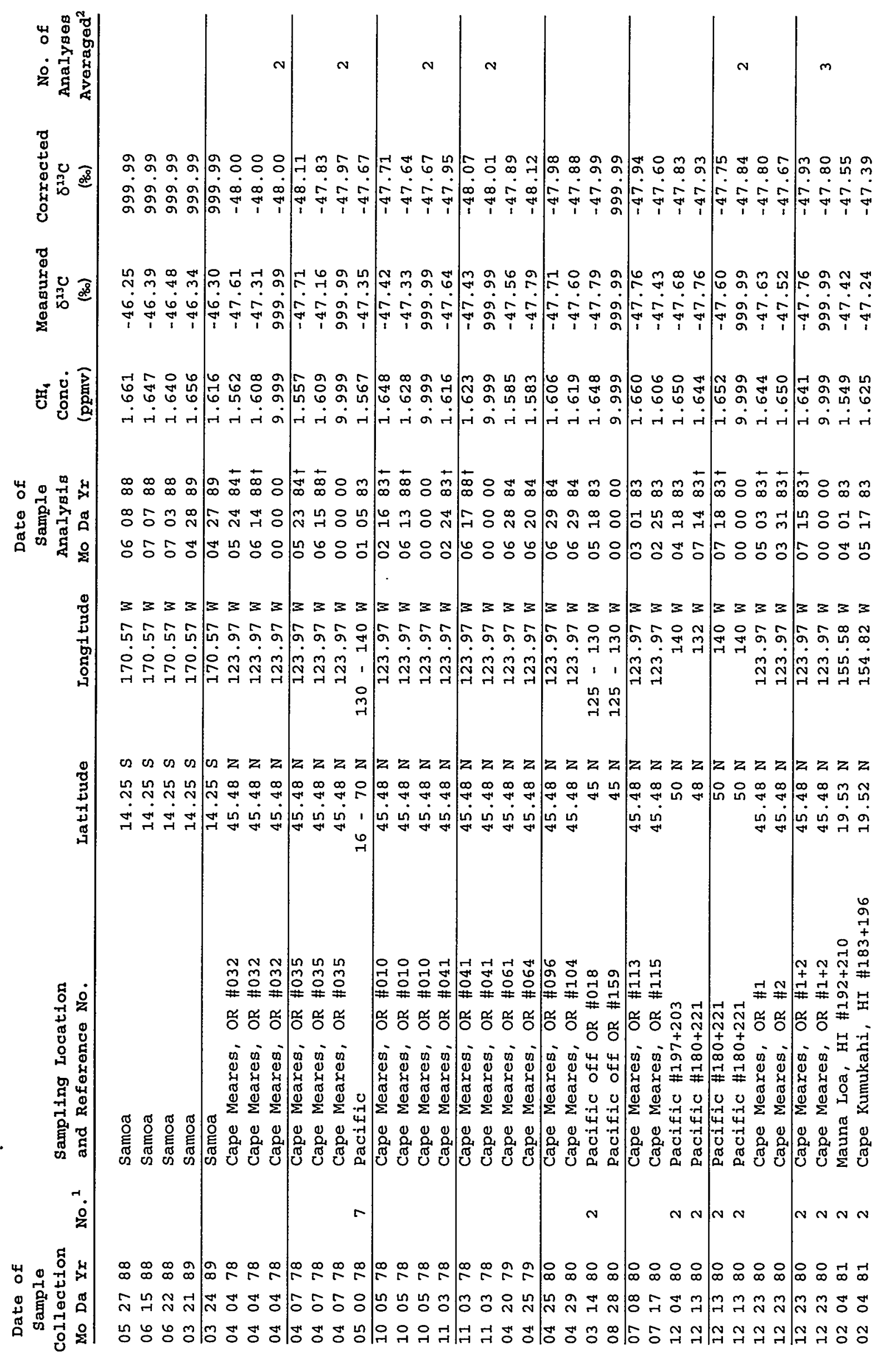



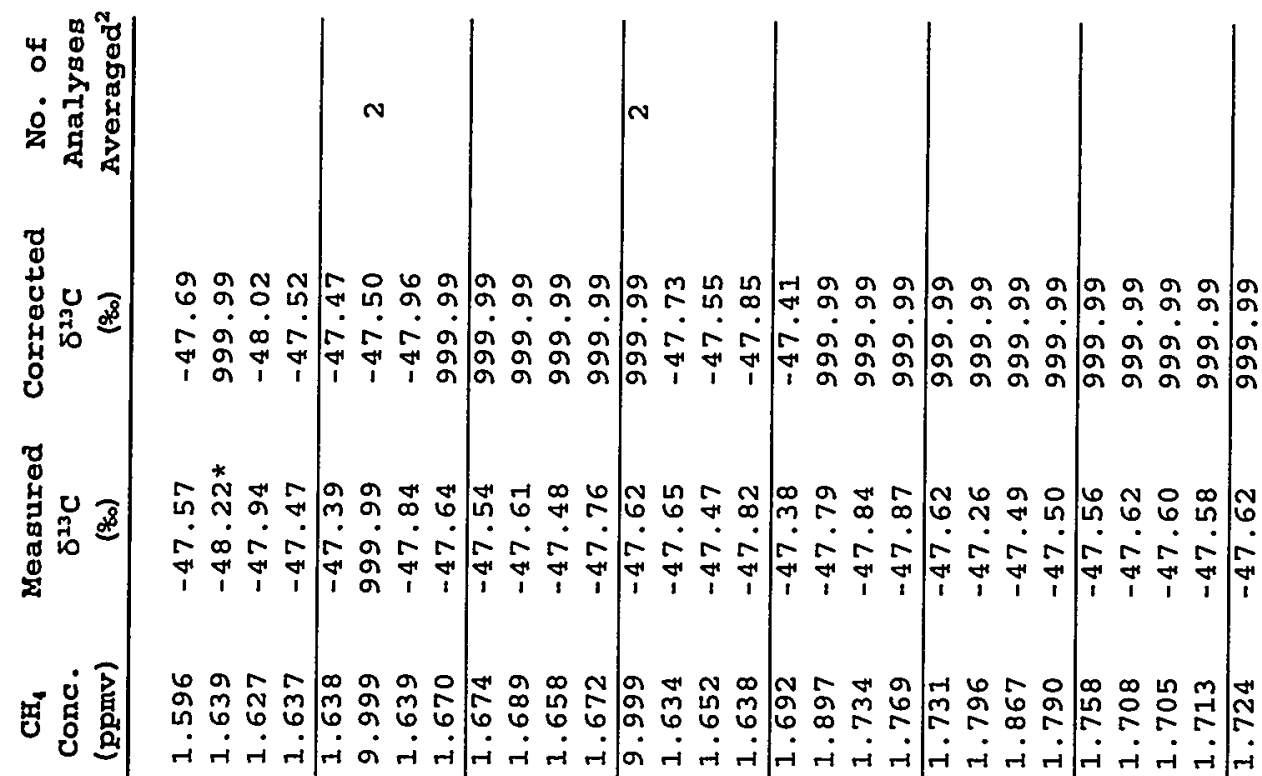

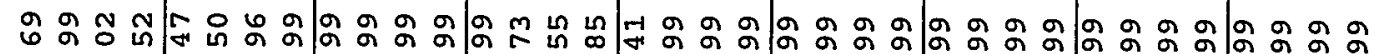
नक

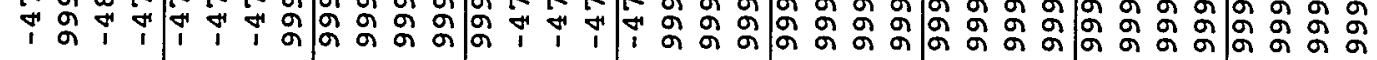

乞ำ

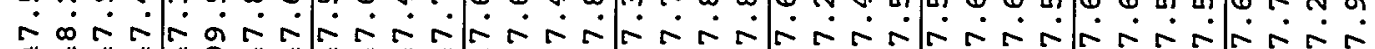

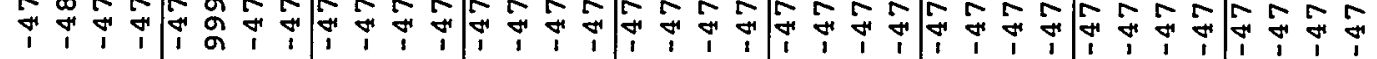

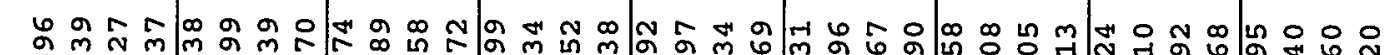
응

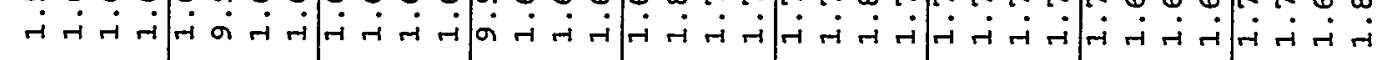

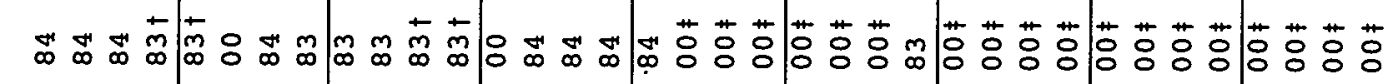
సี

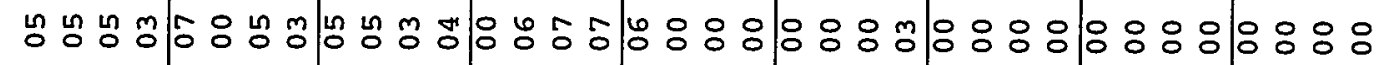

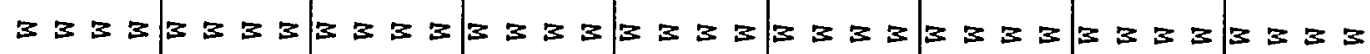

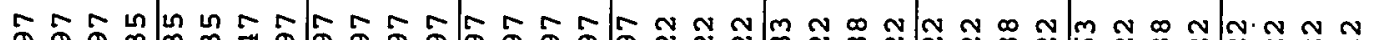

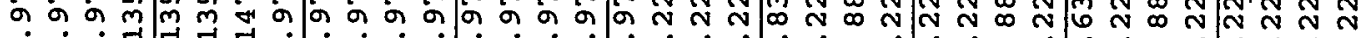

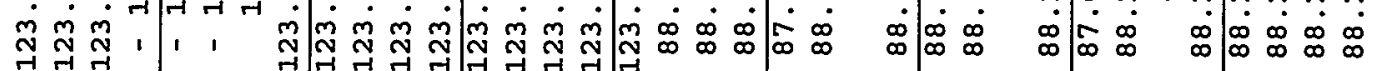

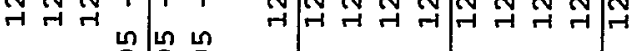

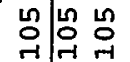

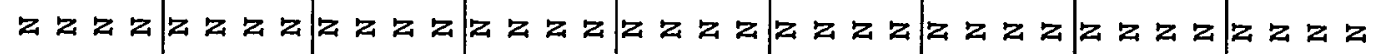

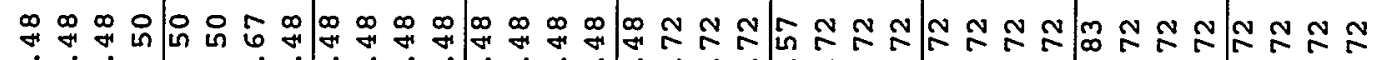

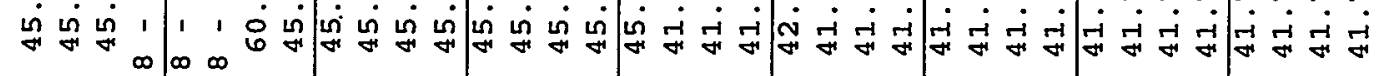

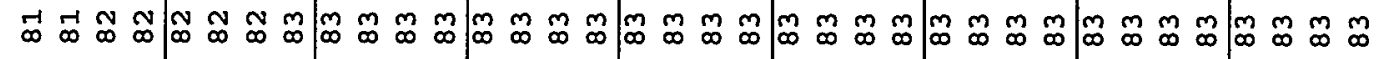

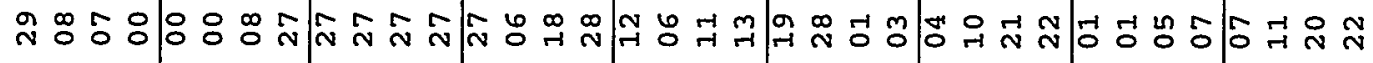

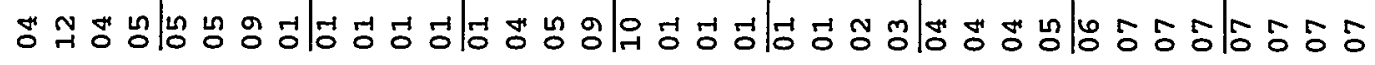


๙ ๙

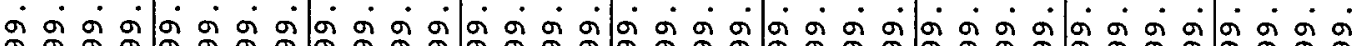
๙

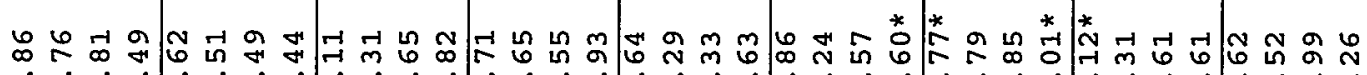

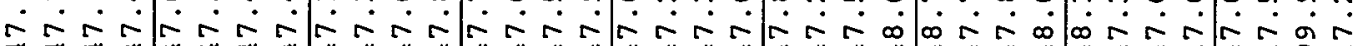

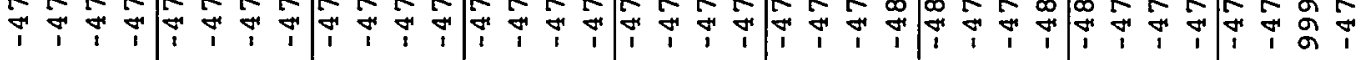

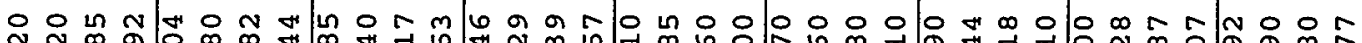
N -

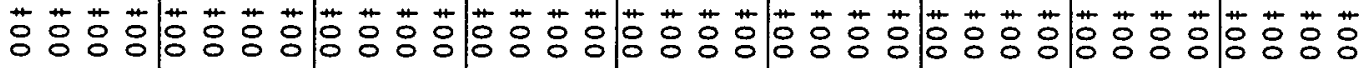
ㅇㅇㅇㅇㅇㅇㅇㅇㅇㅇㅇㅇㅇㅇㅇㅇㅇㅇㅇㅇㅇㅇㅇㅇㅇㅇㅇㅇㅇㅇㅇㅇㅇㅇㅇㅇㅇㅇㅇㅇㅇㅇㅇ은

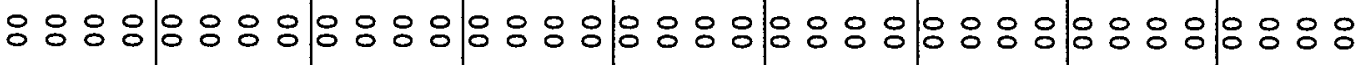

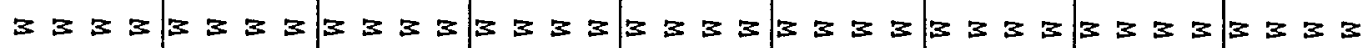

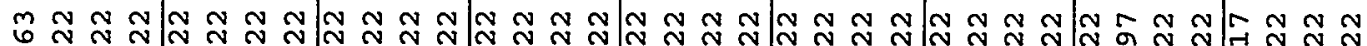

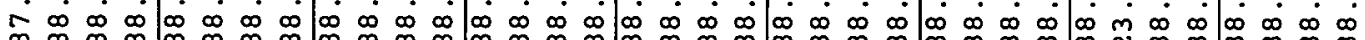

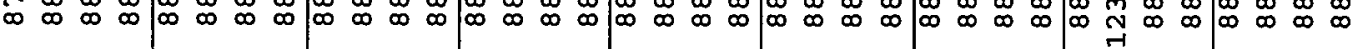

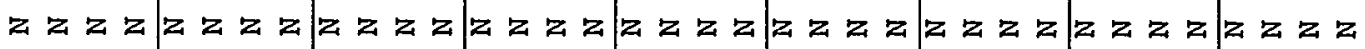
m 尓

$\stackrel{\sim}{0}$

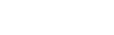

岁,

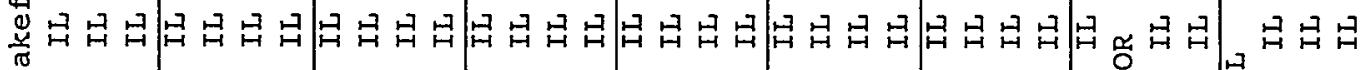

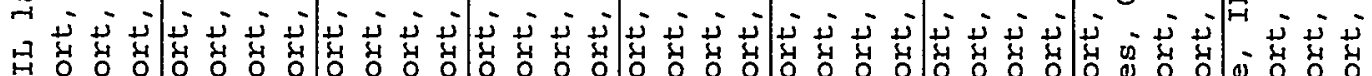

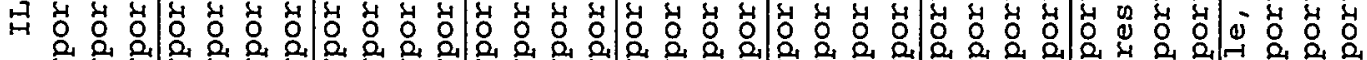

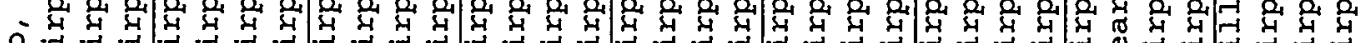
穴

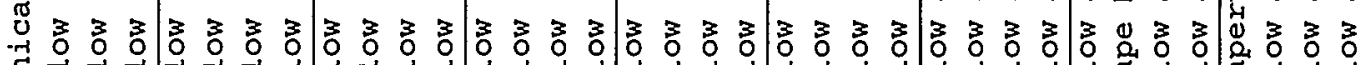

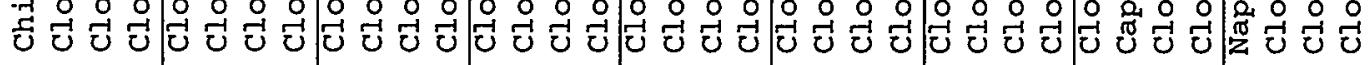

舟

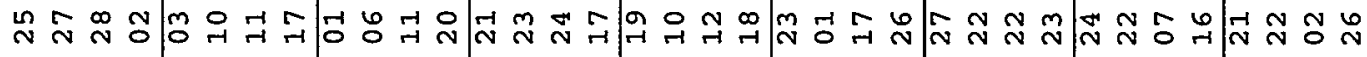

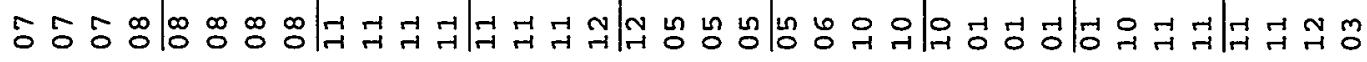




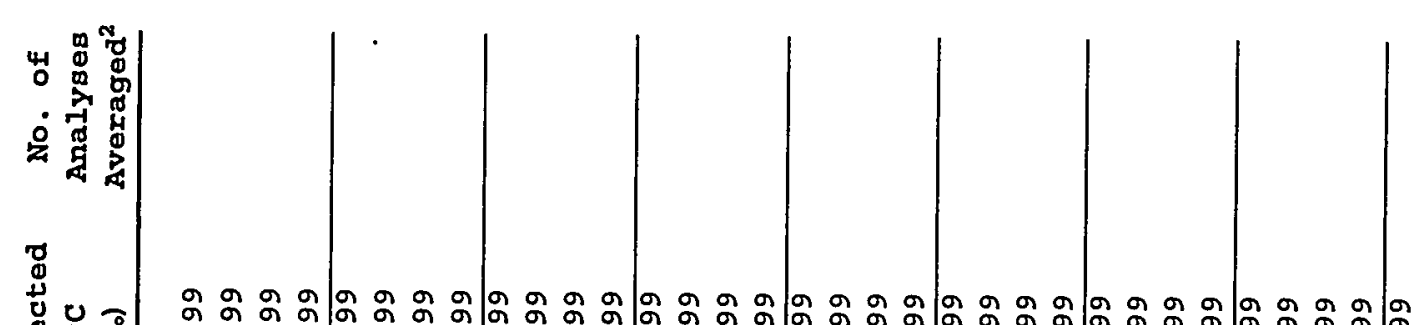

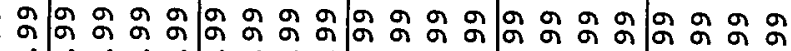

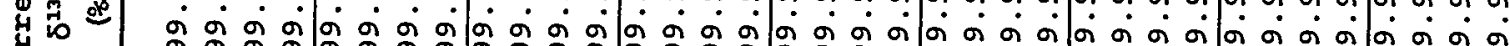
ช

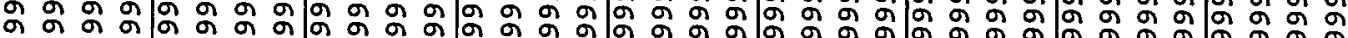

足

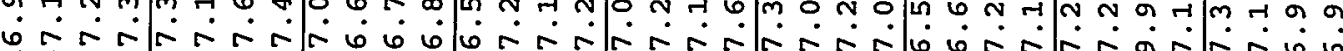

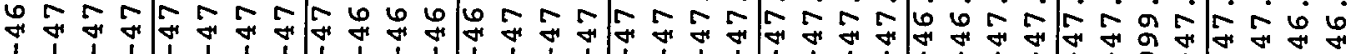

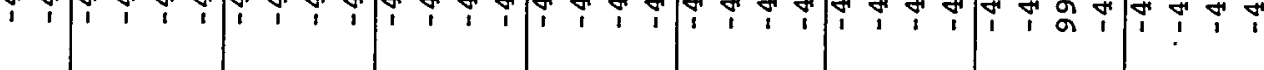

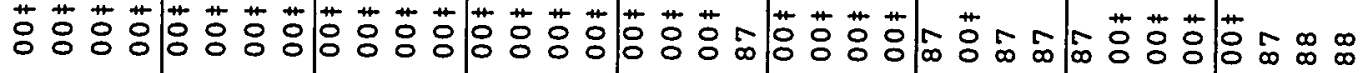

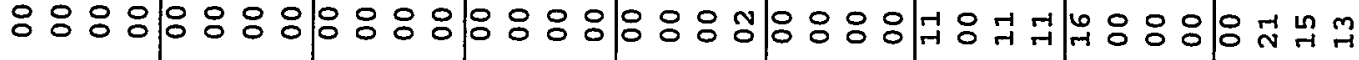

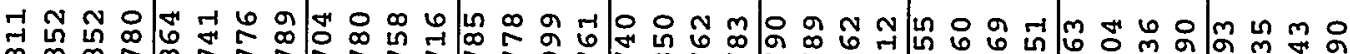

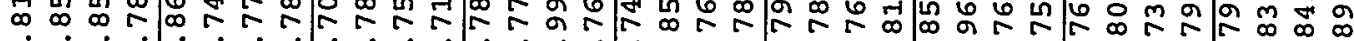
न न ન न ન न : : : : : : : : : :

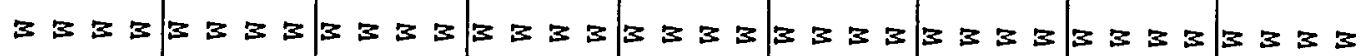
ง

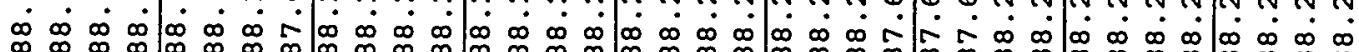

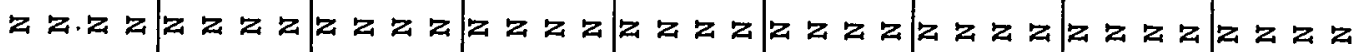
กะง

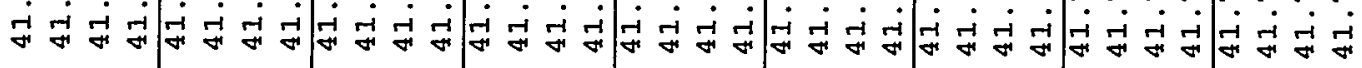

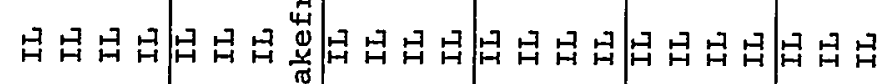

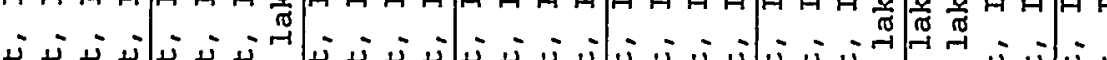

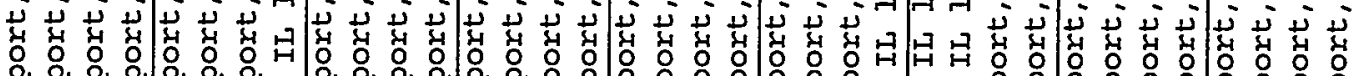

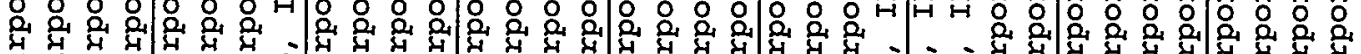
年

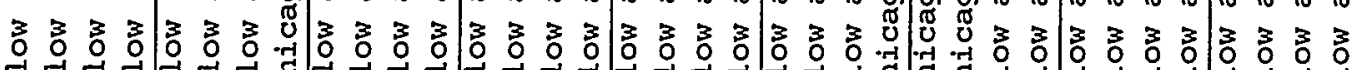

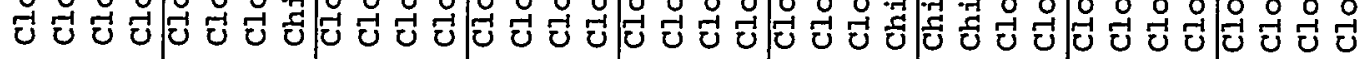




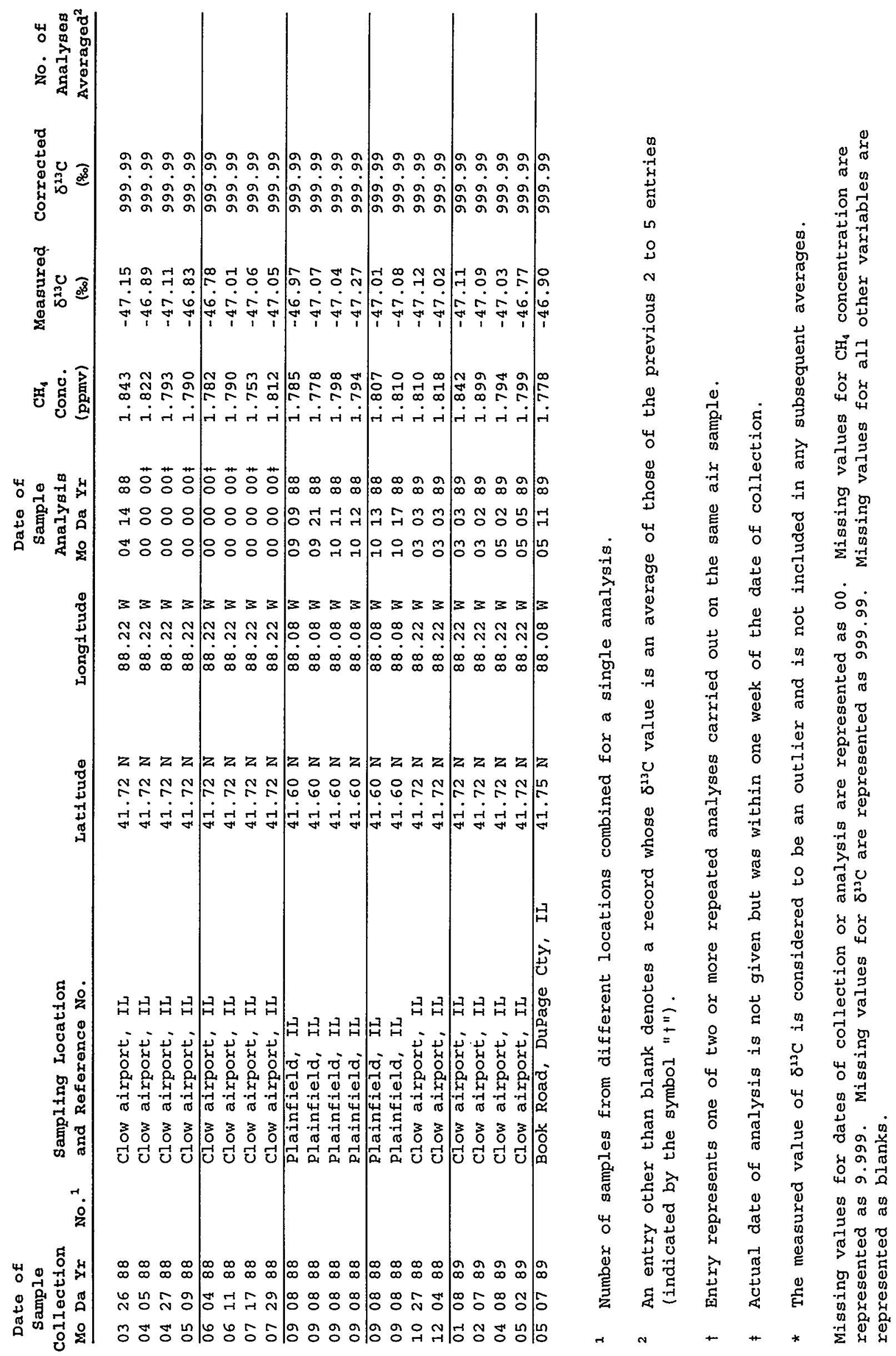




\section{APPENDIX B.}

\section{Reprint of Pertinent Literature}

Isotopic abundances in the atmosphere and sources, by C.M. Stevens. 1993. 


\title{
Reproduced by permission of Springer-Verlag
}

\section{Chapter 4}

\author{
Isotopic Abundances in the Atmosphere and Sources \\ C.M. STEVENS \\ Chemical Technology Division, Argonne National Laboratory, Argonne, IL 60439
}

\section{Introduction}

The ultimate goal of isotopic studies of atmospheric $\mathrm{CH}_{4}$ is to contribute to the understanding of the atmospheric $\mathrm{CH}_{4}$ cycle by determining the relative fluxes from various categories of sources and the causes of the increasing concentration (Stevens and Engelkemeir, 1988; Quay et al.,1988; Wahlen et al., 1989). Because the large number of generic anthropogenic source types makes it impossible to determine their relative strengths based on carbon-13 data alone, Stevens and Engelkemeir (1988) and Craig et al. (1988) used the isotopic data to calculate the flux of the source with the greatest uncertainty, namely biomass burning, making use of the estimated fluxes for the other sources from emission inventories. This method determined the flux and isotopic composition of the natural sources from the concentration and isotopic composition of $\mathrm{CH}_{4}$ in old polar ice cores assuming the same lifetime as now. The lifetime was mostly determined by the fluxes based on the emissions inventories. This approach does not use the lifetime as a constraint nor contribute to the knowledge of the major sources, which have significant uncertainties in the estimates based on emissions inventories. A better approach is to start with the constraint of the lifetime value based on the methyl chloroform cycle (see Mayer et al., 1982; Khalil and Rasmussen, 1983; Prinn et al., 1987; Cicerone and Oremland, 1988). Then it is possible to calculate the fluxes of the two most isotopically different sources, providing an estimate based on emissions inventories for one of the anthropogenic sources is used as a constraint. A source is chosen that introduces the least error, namely landfills, which is one of the smallest and has an isotopic composition closest to the average.

NATO ASI Series, Vol. 113 
Whiticar (this volume) discusses the overall cycles of $\mathrm{CH}_{4}$ formation from the fundamental standpoint of the biogenic and thermogenic pathways and the isotopic fractionation effects at all stages from source generation to loss processes. The diverse and variable conditions for these fractionation effects hinder the isotopic characterization of the various generic sources and therefore the determination of a budget by this method. Examination of the measured values of the $\mathrm{CH}_{4}$ produced by the various generic sources except fossil fuel . sources (see Table 2) shows that they seem to fall in a narrow enough range to permit solving the budget with the practical approach of using these values directly, bypassing the fractionation effects of the formation pathways.

The following sections will summarize the knowledge about the flux strengths of the major anthropogenic sources using only the carbon isotopic results. Use is made of the carbon-14 results for the flux of "dead" $\mathrm{CH}_{4}$ from fossil fuel sources as reported by others; the application of deuterium isotopic data to the atmospheric $\mathrm{CH}_{4}$ is mentioned but not discussed in detail. The average measured isotopic compositions of the $\mathrm{CH}_{4}$ produced by the various generic sources and released to the atmosphere are used to make up a budget whose isotopic composition is constrained to agree with the value determined from the atmospheric composition modified by the fractionation effect of the atmospheric removal process. The most recent determination of the kinetic isotope effect of the reaction $\mathrm{CH}_{4}+\mathrm{OH}$ (Cantrell et al., 1990) is used. The results of calculations for the determination of the relative fluxes of the generic sources are shown subject to conditions for the lifetime. Measurements of the isotopic temporal trends, when considered with the constraints for the unequal distribution between hemispheres of the anthropogenic fluxes, lead to estimates of large increasing fluxes from biomass burning in the southern hemisphere and from natural fluxes in the northern hemisphere.

\section{Isotopic composition of the sources}

Table 1 lists the categories of the major sources of atmospheric $\mathrm{CH}_{4}$ and the averages of the measured values of $\delta^{13} \mathrm{C}$ reported by several laboratories.

Table 2 lists the measurements of $\delta^{13} \mathrm{C}$ for the anthropogenic sources and the average values and 1 standard deviation (SD). These uncertainties were generally about $\pm 0.2 \%$, except in the case of rice $( \pm 0.05)$. The uncertainty for the value for rice has been made greater, $\pm 0.2 \%$, to reflect an uncertainty from the lack of samples in the principal global rice growing areas. The uncertainty for the $\delta^{13} \mathrm{C}$ of $\mathrm{CH}_{4}$ from fossil fuels has been increased ( $\pm 0.4 \%$ ) from the indicated SD ( $\pm 0.2 \% 0)$ of the measured values because of the very wide spread in the values and the uncertain distribution of a global emissions inventory. The non-anthropogenic source, sometimes called the "natural source," is not directly related to man's activities and consists of natural wetlands of all types, forest and savanna fires caused by lightning, oceans and lakes, any possible leakages from natural gas deposits, and termites. Natural wetlands constitute the major natural source. 
Table 1. The carbon-13 isotopic composition of the sources of atmospheric $\mathrm{CH}_{4}$. The uncertainty is estimated at $\pm 0.2 \%$, except (a), which is $\pm 0.4 \%$.

\begin{tabular}{ll}
\hline Source & $\delta^{13} \mathrm{C}$ \\
\hline Natural (all non-anthropogenic) & -56.7 \\
Rice Paddies & -64 \\
Herbivores & -60 \\
Landfills & -52 \\
Natural Gas & $-43(\mathrm{a})$ \\
Coal Mining & $-37(\mathrm{a})$ \\
Biomass Burning & -22 \\
\hline
\end{tabular}

Table 2. The carbon isotopic compositions of the anthropogenic sources of atmospheric $\mathrm{CH}_{4}$.

\begin{tabular}{|c|c|c|c|}
\hline Source & $\begin{array}{l}\text { Method and } \\
\text { number of samples }\end{array}$ & $\begin{array}{l}\text { Mean } \delta^{13} \mathrm{C} \text { and } \\
\text { range }(\% 0)\end{array}$ & Reference \\
\hline \multicolumn{4}{|l|}{ RICE PADDIES } \\
\hline $\begin{array}{l}\text { California } \\
\text { Louisiana } \\
\text { Kenya } \\
\text { Vercelli, Italy } \\
\text { Average } \\
\end{array}$ & $\begin{array}{l}\text { Inversion (4) } \\
\text { Flux Chamber (8) } \\
\text { Flux Chamber (10) } \\
\text { Flux Chamber (7) }\end{array}$ & $\begin{array}{l}-67(-66 \text { to }-68) \\
-63.2 \pm 2.9 \\
-59.4(-57 \text { to }-63) \\
-65.4 \pm 1.6 \\
-63.8 \pm 1.5 \\
\end{array}$ & $\begin{array}{l}\text { Stevens and } \\
\text { Engelkemeir, } 1988 \\
\text { Wahlen et al., } 1989 \\
\text { Tyler et al., } 1988 \\
\text { Levin et al., } 1993\end{array}$ \\
\hline \multicolumn{4}{|c|}{ RUMINANTS $C_{3}$ Diet } \\
\hline $\begin{array}{l}\text { Cattle } \\
\text { Cattle } \\
\text { Sheep } \\
\text { Cattle } \\
\text { Cattle } \\
\text { Sheep } \\
\text { Goat } \\
\text { Average } \\
\end{array}$ & $\begin{array}{l}\text { Fistula (5) } \\
\text { Barn (1) } \\
\text { Fistula (2) } \\
\text { Barn (4) } \\
\text { Bag (1) } \\
\text { Bag (1) } \\
\text { Bag (1) }\end{array}$ & $\begin{array}{l}-63.7(-61 \text { to }-76) \\
-61.1 \\
-68.6(-67 \text { to }-70) \\
-71.3 \pm 4 \\
-65.1 \pm 1.7 \\
-70.6 \\
-65.2 \\
-6.3 \pm 1.0\end{array}$ & $\begin{array}{l}\text { Rust, } 1981 \\
\text { Rust, } 1981 \\
\text { Rust, } 1981 \\
\text { Wahlen et al., } 1989 \\
\text { Levin et al., } 1993 \\
\text { Levin et al., } 1993 \\
\text { Levin et al., } 1993\end{array}$ \\
\hline \multicolumn{4}{|c|}{ RUMINANTS $\mathrm{C}_{4}$ Diet } \\
\hline $\begin{array}{l}\text { Cattle } \\
\text { Cattle } \\
\text { Cattle }\left(60-80 \% \mathrm{C}_{4}\right. \\
\text { diet }) \\
\quad \text { Average } \\
\end{array}$ & $\begin{array}{l}\text { Fistula (3) } \\
\text { Barn (1) } \\
\text { Bag (3) }\end{array}$ & $\begin{array}{l}-50.3(-47 \text { to }-51) \\
-45.4 \\
-55.6 \pm 1.4 \\
-50 \pm 3\end{array}$ & $\begin{array}{l}\text { Rust, } 1981 \\
\text { Rust, } 1981 \\
\text { Levin et al., } 1993\end{array}$ \\
\hline \multicolumn{4}{|l|}{ LANDFILLS } \\
\hline $\begin{array}{l}\text { Colorado } \\
\text { Heidelberg } \\
\text { Average }\end{array}$ & $\begin{array}{l}\text { Flux chamber (2) } \\
\text { Upper layers (1) }\end{array}$ & $\begin{array}{l}-50(-48 \text { to }-52) \\
-53(-51 \text { to }-55 Z) \\
-52 \\
-52 \pm 2\end{array}$ & $\begin{array}{l}\text { Games \& Hayes, } \\
1976 \\
\text { Tyler, } 1986 \\
\text { Levin et al., } 1993\end{array}$ \\
\hline \multicolumn{4}{|l|}{ NATURAI GAS } \\
\hline $\begin{array}{l}\text { Thermogenic 20\% } \\
\text { Biogenic } 80 \% \\
\text { Average }\end{array}$ & . & $\begin{array}{l}-38(-25 \text { to }-52) \\
-65(-60 \text { to }-70) \\
-43 \pm 4(a)\end{array}$ & $\begin{array}{l}\text { Schoell, } 1980 \\
\text { Rice \& Claypool, } \\
1981\end{array}$ \\
\hline
\end{tabular}


Table 2. The carbon isotopic compositions of the anthropogenic sources of atmospheric $\mathrm{CH}_{4}$.

\begin{tabular}{llll}
\hline Source & $\begin{array}{l}\text { Method and } \\
\text { number of samples }\end{array}$ & $\begin{array}{l}\text { Mean } \delta^{13} \mathrm{C} \text { and } \\
\text { range }(\% 0)\end{array}$ & Reference \\
\hline COAL MINING & & $\begin{array}{l}-37 \pm 4(-14 \text { to } \\
-60)\end{array}$ & Deines, 1980 \\
\hline \multicolumn{2}{l}{ BIOMASS BURNING } & & \\
Wood fire & Plume (3) & $-27(-24$ to -32$)$ & $\begin{array}{l}\text { Stevens \& } \\
\text { Engelkemeir, 1988 }\end{array}$ \\
Grass fire & Plume (1) & -32 & "1 \\
Brush fire & Plume (2) & -26.6 & Wahlen et al., 1989 \\
Wood fire & Plume (1) & -26.4 & Levin et al., 1993 \\
\hline
\end{tabular}

Table 3 lists the measurements of the isotopic composition of $\mathrm{CH}_{4}$ emitted from or contained in the sediment gases of the various natural wetlands, such as the arctic tundra, Amazon floodplain, peatlands, Everglades marsh and temperate marshes, lakes and ponds, and estuaries. However, it would be difficult to

Table 3. The carbon isotopic composition of $\mathrm{CH}_{4}$ emitted from or contained in sediments of various natural wetlands.

\begin{tabular}{|c|c|c|c|}
\hline Wetlands & Sampling Method & $\begin{array}{l}\text { Mean } \delta^{13} \mathrm{C} \text { and } \\
\text { Range (\%o) }\end{array}$ & Reference \\
\hline Alaska tundra & Flux chamber & $-66(-55$ to -73$)$ & Quay et al., 1988 \\
\hline " & Bubbles & $-62(-57$ to -72$)$ & Quay et al., 1988 \\
\hline Canadian tundra & Surface & $-63 \pm 1.9$ & $\begin{array}{l}\text { Wahlen et al., } \\
1989\end{array}$ \\
\hline USSR marshes & Not specified & $-64(-52$ to -69$)$ & $\begin{array}{l}\text { Ovsyannikov \& } \\
\text { Lebedev, } 1967\end{array}$ \\
\hline $\begin{array}{l}\text { New England } \\
\text { Lakes }\end{array}$ & Mud gases & $-69(-57$ to -80$)$ & $\begin{array}{l}\text { Oona \& Deevey, } \\
1960\end{array}$ \\
\hline $\begin{array}{l}\text { New York } \\
\text { wetlands }\end{array}$ & Surface & $-58 \pm 2.4$ & $\begin{array}{l}\text { Wahlen et al., } \\
1989\end{array}$ \\
\hline $\begin{array}{l}\text { Minnesota peat } \\
\text { bog }\end{array}$ & Inversion & $-67(-64$ to -71$)$ & $\begin{array}{l}\text { Stevens \& } \\
\text { Engelkemeir, } 1988\end{array}$ \\
\hline$"$ & Flux chamber & $-66(-57$ to -77$)$ & Quay et al., 1988 \\
\hline$"$ & Bubbles & $-66(-50$ to -86$)$ & Quay et al., 1988 \\
\hline Amazon River & Surface & -64 & Tyler, 1986 \\
\hline $\begin{array}{l}\text { Kenya papyrus } \\
\text { swamp }\end{array}$ & Flux chamber & $-51(-31$ to -62$)$ & Tyler et al., 1988 \\
\hline Kenya river & Flux chamber & -54 & Tyler et al., 1988 \\
\hline Kenya lake & Flux chamber & $-48(-44$ to -50$)$ & Tyler et al., 1988 \\
\hline $\begin{array}{l}\text { Amazon flood } \\
\text { plain }\end{array}$ & Bubbles, 1985 & $-62(-47$ to -73$)$ & Quay et al., 1988 \\
\hline
\end{tabular}


Table 3. The carbon isotopic composition of $\mathrm{CH}_{4}$ emitted from or contained in sediments of various natural wetlands.

\begin{tabular}{|c|c|c|c|}
\hline Wetlands & Sampling Method & $\begin{array}{l}\text { Mean } \delta^{13} \mathrm{C} \text { and } \\
\text { Range (\%o) }\end{array}$ & Reference \\
\hline$"$ & Bubbles, 1987 & $-52(-42$ to -60$)$ & $"$ \\
\hline$"$ & Dissolved in lakes & $-56(-41$ to -66$)$ & $"$. \\
\hline$"$ & Flux chamber & $-51(-42$ to -73$)$ & $"$ \\
\hline " & Inversion & $-52(-49$ to -56$)$ & $"$ \\
\hline Florida Everglades & Inversion & $-55(-53$ to -58$)$ & $\begin{array}{l}\text { Stevens \& } \\
\text { Engelkemeir, } 1988\end{array}$ \\
\hline$"$ & Sediment bubbles & $-65(-63$ to -70$)$ & $\begin{array}{l}\text { Chanton et al., } \\
1988\end{array}$ \\
\hline $\begin{array}{l}\text { Florida, Crescent } \\
\text { Lake }\end{array}$ & Flux chamber & $-64(-79$ to -71$)$ & $\begin{array}{l}\text { Burke \& Sackett, } \\
1986\end{array}$ \\
\hline $\begin{array}{l}\text { Florida, Mirror } \\
\text { Lake }\end{array}$ & $"$ & $-55(-52$ to -56$)$ & $"$ \\
\hline Florida, Lake Dias & $"$ & $-63(-60$ to -67$)$ & $"$ \\
\hline Miss. River Delta & $"$ & $-60(-59$ to -60$)$ & $"$ \\
\hline $\begin{array}{l}\text { South Carolina } \\
\text { pond }\end{array}$ & $"$ & $-53(-51$ to -55$)$ & $"$ \\
\hline $\begin{array}{l}\text { Florida, Tampa } \\
\text { Bay estuary }\end{array}$ & $"$ & $-66(-63$ to -71$)$ & $"$ \\
\hline Colorado pond & " & $-53(-52$ to -54$)$ & Tyler, 1986 \\
\hline $\begin{array}{l}\text { North Carolina } \\
\text { marine basin }\end{array}$ & Bubbles & $-60+2$ (summer) & $\begin{array}{l}\text { Chanton \& } \\
\text { Martens, } 1988\end{array}$ \\
\hline " & Flux chamber & $-67(-66$ to -70$)$ & $"$ \\
\hline Illinois slough & Flux chamber & $-50(-49$ to -51$)$ & $\begin{array}{l}\text { Stevens \& } \\
\text { Engelkemeir, } 1988\end{array}$ \\
\hline$"$ & Sediment gases & $-56(-55$ to -58$)$ & " \\
\hline $\begin{array}{l}\text { Swamp, } \\
\text { Heidelberg, } \\
\text { Germany }\end{array}$ & Flux chamber & $-57 \pm 2$ & Levin et al., 1993 \\
\hline
\end{tabular}

determine the global average isotopic composition of all of the natural sources from these data because the relative emission inventories of the contributions from the various natural wetlands types, as well as other natural sources such as forest fires, cannot be easily ascertained. A direct measure of this average value can be taken from the isotopic composition of atmospheric $\mathrm{CH}_{4}$ for a time when anthropogenic emissions were negligible, assuming the makeup of the natural sources has remained the same. Methane in the air contained in 100- to 300year-old ice cores has $\delta^{13} \mathrm{C}=-49.6 \pm 0.7 \%$ (Craig et al., 1988); this leads to the average value for all the natural sources at that time of $-55.7 \%$, after applying the correction $\Theta=-6.0$ for the fractionating factor $\alpha=0.994$ (Cantrell et al., 
1990) of the atmospheric loss processes, where $\Theta=(\alpha-1)\left(1+10^{-3} \delta^{13} \mathrm{C}_{\mathrm{atm}}\right)$. The fractionation factor of the atmospheric loss processes is the ratio of the loss rates of ${ }^{13} \mathrm{CH}_{4}$ and ${ }^{12} \mathrm{CH}_{4}$, mainly the relative oxidation rates of the reaction of $\mathrm{CH}_{4}$ by $\mathrm{OH}$ radicals. Assuming that the fluxes of all the component natural sources have not changed in the interim, the value at the present time would be -56.7 \%o due to a small correction of $-1 \%$ for the decreasing carbon-13 abundance of atmospheric $\mathrm{CO}_{2}$ caused by contributions from fossil fuel burning (Keeling et al., 1979; Friedli et al., 1986).

The major natural source is the emission from the natural wetlands. The isotopic composition of the northern wetlands, including the regions of the arctic tundra and peatlands and some of the Amazon flood plains and Florida Everglades, falls in the range -60 to $-70 \%$ with an average of about $-65 \%$ (Table 3). More enriched values of $\mathrm{CH}_{4}$, up to $-50 \%$, are observed for some northern mid-latitude lakes and ponds and some regions of the Amazon and the Florida Everglades. It is likely that the difference between $-57 \%$, the average for all natural sources derived from the atmospheric $\mathrm{CH}_{4}$ in old polar ice cores, and $-65 \%$, for the major natural wetlands, is at least partially accounted for by isotopically heavy $\mathrm{CH}_{4}$ emissions from natural forest and savanna fires.

The value of $-64 \%$ shown for rice is the average of the measurements by Stevens and Engelkemeir (1988), Tyler et al. (1988), Wahlen et al. (1989), and Levin et al. (1993) and is very close to the average value for $\mathrm{CH}_{4}$ from the majority of natural wetlands. For $\mathrm{CH}_{4}$ from herbivores the value $-60 \% 0$ is used, which is based on the comprehensive study by Rust (1981). The values of -43 \%o for natural gas and $-37 \%$ for coal mining are based on the means of the extensive compilations of Schoell (1980), Deines (1980), and Rice and Claypool (1981). These values are averages of available data and not weighted for the geographic flux distributions except for an estimated ratio of thermogenic and biogenic gas sources. For $\mathrm{CH}_{4}$ from biomass burning a value of $\delta^{13} \mathrm{C}=-22 \% 0$ is used. This value is the weighted average of $80 \%$ due to $C_{3}$ plants and trees with an average isotopic composition of $-25 \%$ (Craig, 1953) and $20 \%$ due to $\mathrm{C}_{4}$ plants of tropical savanna fires with $\delta^{13} \mathrm{C}=-12 \%$. The measured values show little fractionation by the burning process from the isotopic composition of the biomass (Stevens and Engelkemeir, 1988; Wahlen et al., 1989). In order to reduce the number of independent variables, the $\mathrm{CH}_{4}$ from rice paddies and herbivores are combined as a single generic source with an average $\delta^{13} \mathrm{C}$ of -62 $\% o$, based on the emissions inventories of the relative fluxes. The fluxes from natural gas and coal mining can be combined into one generic fossil fuel source with an average value of $-41 \%$, since the isotopic compositions are similar and both contain $100 \%$ "dead" carbon, i.e., no carbon-14.

\section{Isotopic composition of atmospheric methane}

Measurements of $\delta^{13} \mathrm{C}$ of atmospheric $\mathrm{CH}_{4}$ that have been done by various groups are listed in Table 4 and plotted in Figure 1. They agree well enough to determine the average value of the sources but not well enough to compare with 
Table 4. Comparison of measurements of the carbon-13 isotopic composition of atmospheric $\mathrm{CH}_{4}$; errors are $1 \mathrm{SD}$ with numbers of samples in parentheses.

\begin{tabular}{|c|c|c|c|}
\hline Laboratory & Year & $\begin{array}{l}\delta^{13} \mathrm{C} \% \text { Southern } \\
\text { Hemisphere }\end{array}$ & $\begin{array}{l}\delta^{13} \mathrm{C} \% 0 \text { Northern } \\
\text { Hemisphere }\end{array}$ \\
\hline \multirow[t]{2}{*}{$A$} & 1978.5 & $-47.84 \pm .05(4)$ & \\
\hline & 1978.8 & & $-47.88 \pm .14(7)$ \\
\hline$"$ & 1980.5 & $-47.52 \pm .09(3)$ & $-47.78 \pm .08(5)$ \\
\hline$"$ & 1981.5 & $-47.49 \pm .09(3)$ & $-47.69 \pm .02(7)$ \\
\hline$"$ & 1982.5 & $-47.35 \pm .04(4)$ & $-47.74 \pm .26(4)$ \\
\hline$"$ & 1983.25 & & $-47.60 \pm .05(20)$ \\
\hline$"$ & 1983.5 & & $-47.61 \pm .05(7)$ \\
\hline$"$ & 1983.75 & & $-47.61 \pm .04(20)$ \\
\hline$"$ & 1984.2 & $-47.15 \pm .15(1)$ & \\
\hline$"$ & 1984.5 & & $-47.53 \pm .10(5)$ \\
\hline$"$ & 1985.5 & & $-47.66 \pm .08(5)$ \\
\hline$"$ & 1986.25 & & $-47.28 \pm .06(11)$ \\
\hline$"$ & 1986.75 & & $-47.25 \pm .06(10)$ \\
\hline$"$ & 1986.9 & $-46.71 \pm .08(6)$ & \\
\hline$"$ & 1987.5 & & $-47.21 \pm .10(6)$ \\
\hline$"$ & 1988.25 & & $-46.98 \pm .05(15)$ \\
\hline$"$ & 1988.3 & $-46.49 \pm .09(6)$ & \\
\hline$"$ & 1989.25 & & $-47.00 \pm .10(7)$ \\
\hline$"$ & 1989.3 & $-46.32 \pm .10(2)$ & \\
\hline B & 1976.5 & & $-47.3 \pm .2(1)$ \\
\hline$"$ & 1977.5 & & $-46.9 \pm .2(1)$ \\
\hline$"$ & 1978.5 & & $-46.5 \pm .2(1)$ \\
\hline$"$ & 1986.5 & & $-46.7 \pm .3(27)$ \\
\hline$"$ & 1986.8 & $-46.0 \pm .2(5)$ & \\
\hline$"$ & 1987.5 & $-45.2 \pm .3(2)$ & $-46.5 \pm .2(11)$ \\
\hline$"$ & 1988.0 & $-46.6 \pm .3(4)$ & \\
\hline C & 1987 to & $-47.04 \pm .2(5)$ & -47.35 to \\
\hline$"$ & 1989 & & $-47.20 \pm .13(208)$ \\
\hline D & 1985.5 & & -46.5 \\
\hline$E$ & $\begin{array}{l}1989.6 \text { to } \\
1991.8\end{array}$ & $-47.14 \pm .03(90)$ & \\
\hline
\end{tabular}

\#: Stevens, 1988. B: Wahlen et al., 1989. C: Quay et al., 1988. D: Tyler, 1986. E: Lassey et al., 1993.

each other for temporal trends or latitude gradients. There may be small real differences among these values due to different locations of sample collection, but the main differences are most likely caused by differences in sample preparation and calibration of the working isotopic standards used in the mass spectrometric analysis. Accurate calibration is a difficulty inherent in trying to establish to $\pm 0.1 \%$ the absolute accuracy of samples that differ by the large amount of $-47 \% 0$ from the Peedee belemnite carbonate used as the common reference. 


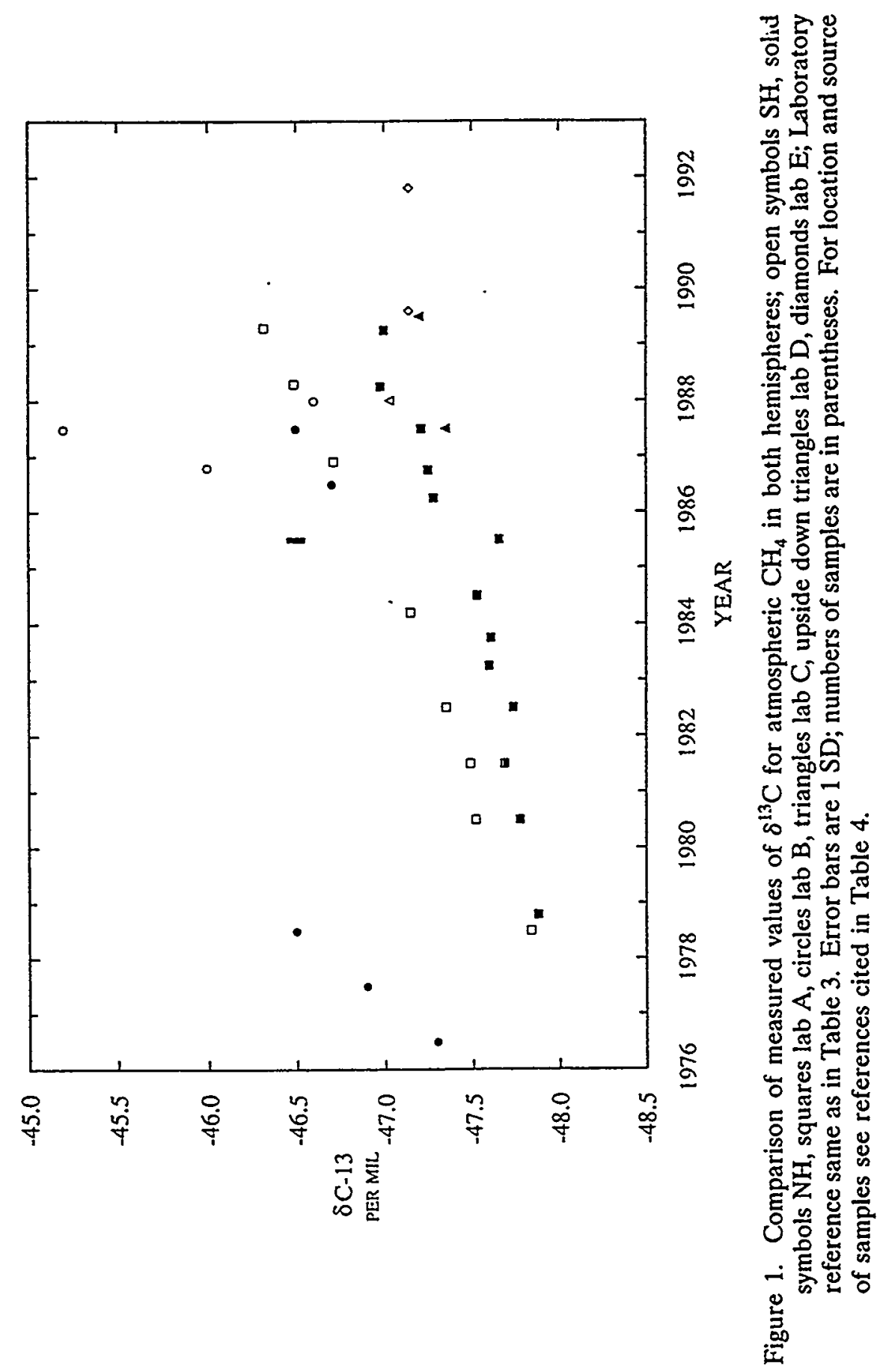




\section{Calculation of source budgets}

The overall objective is to determine the relative, if not absolute, fluxes of the five generic types of sources of atmospheric $\mathrm{CH}_{4}$. There are only three constraints based on measurable quantities of the overall $\mathrm{CH}_{4}$ cycle; two of them are the two mass balance equations for ${ }^{12} \mathrm{CH}_{4}$ and ${ }^{13} \mathrm{CH}_{4}$ for the current (1978) condition of atmospheric $\mathrm{CH}_{4}$.

$$
\begin{gathered}
d C / d t=\Sigma F_{i}-C / \tau \\
d\left(C \delta_{A}\right) / d t=\Sigma F_{i} \delta_{i}-C\left(\delta_{2}+\Theta\right) / \tau
\end{gathered}
$$

where $C$ is the atmospheric burden in teragrams, $F_{i}$ the individual fluxes, $\delta_{i}$ the isotopic composition of the sources, $\delta_{\mathrm{A}}$ the average atmospheric isotopic composition, $\tau$ the lifetime and $\Theta$ the average fractionation factor of the atmospheric loss processes ( $-6.0 \%$ ). A third constraint is the abundance of ${ }^{14} \mathrm{CH}_{4}$ in atmospheric $\mathrm{CH}_{4}$, which determines the fraction of $\mathrm{CH}_{4}$ from fossil fuel sources at 16 to $21 \%$ of the total flux in 1987 (Wahlen et al., 1989; Quay et al., 1991; Lowe et al., 1991). The reference year for these calculations is 1978; back correcting for the growth rates of $2.75 \% / y r$ of both global natural gas and coal production (see Figure 2) exceeding the concentration growth by $1.75 \% / y r$, the flux from these combined sources in 1978 would have been 13 to $17 \%$ of the total flux or 60 to $80 \mathrm{Tg} / \mathrm{yr}$ if the total flux was $460 \mathrm{Tg} / \mathrm{yr}$ for a lifetime of 10 years. The mass balance equations for ${ }^{12} \mathrm{CH}_{4}$ and ${ }^{13} \mathrm{CH}_{4} 100$ to 300 years ago, based on measurements of $\mathrm{CH}_{4}$ in old polar ice cores when the concentration was $45 \%$ of that in 1978 and representing mainly natural sources (Craig and Chou, 1982; Craig et al., 1988), are important for determining the average isotopic composition of the natural sources, $\delta^{13} \mathrm{C}=-56.7 \%$. The ${ }^{12} \mathrm{CH}_{4}$ mass balance might seem to supply another constraint for the natural flux, but the lifetime at that time is another unknown, making for no net change in the number of degrees of freedom. Using the constraints cited above, the solution for the unknown fluxes is under-determined with an excess of three degrees of freedom, the unknown lifetime for the ice-core $\mathrm{CH}_{4}$ and the fluxes of the following sources: combined rice and herbivores, landfills, and biomass burning. Assuming the lifetime at the time the methane was trapped in the polar ice was the same as now, then the fluxes of two of the sources can be expressed in terms of a third. This is as far as the calculation of a budget can be done based on carbon isotopic data alone. To proceed further the emissions inventories estimate for one of the sources is used. Using the estimate for landfills introduces the least uncertainty. This estimate is $50 \pm 20 \mathrm{Tg} / \mathrm{yr}$ (Bingemer and Crutzen, 1987). On this basis Table 5 lists the fluxes calculated for the fluxes of all the sources. These results show that for a lifetime of ten years the calculated combined fluxes from rice and herbivores of $110 \mathrm{Tg} / \mathrm{yr}$ disagrees by a large amount with the emissions inventory estimate of $180 \pm 60 \mathrm{Tg} / \mathrm{yr}$. Also, the values for the natural fluxes based on the $\mathrm{CH}_{4}$ in polar ice cores are much greater than the emissions inventory estimate by Matthews and Fung (1987). With a lifetime of 8 years, the discrepancy 

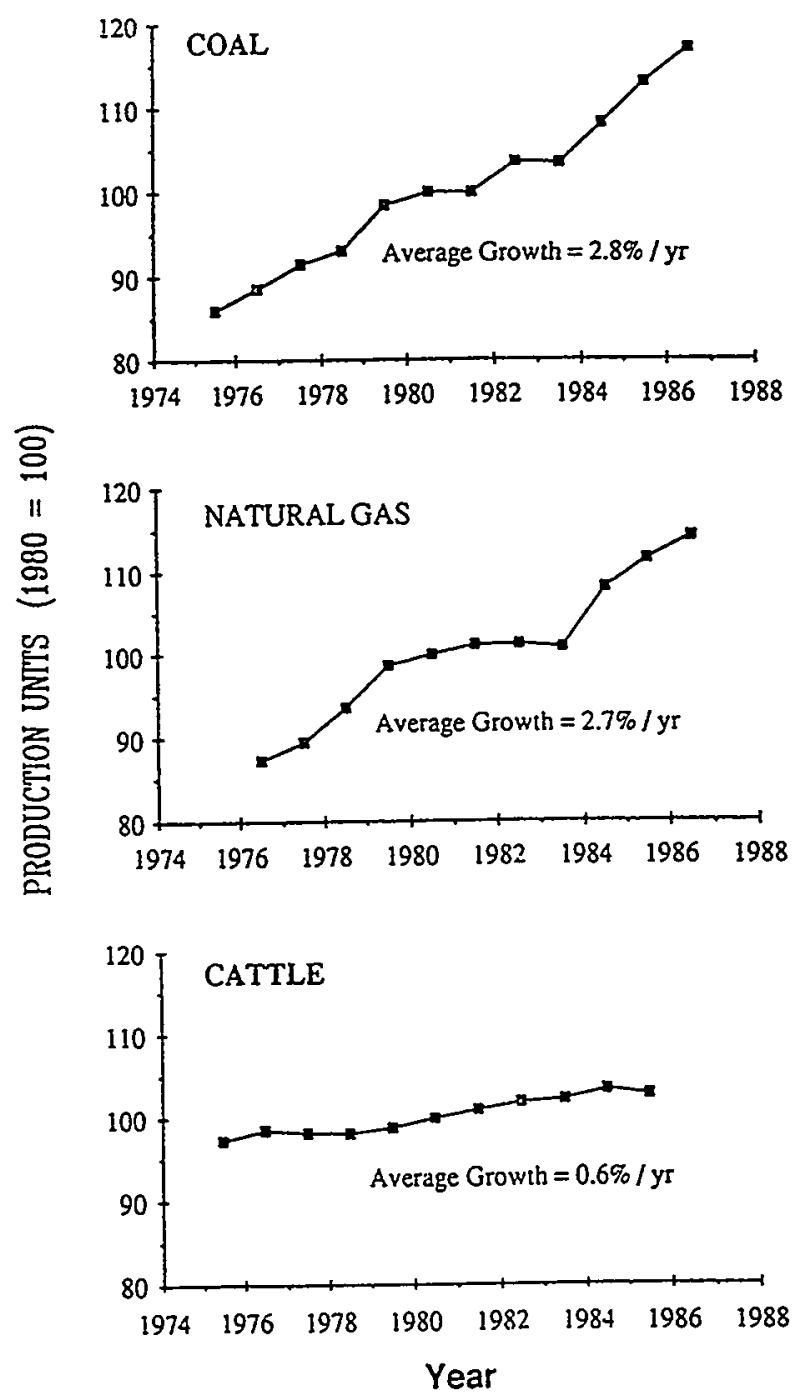

Figure 2. The growth rate for the global production of hard coal, natural gas, and cattle. Production units are based on setting the values for the year 1980 equal to 100 (from United Nations Statistical Yearbooks).

between the calculated values and the emissions inventory estimate becomes smaller for the combined rice and cattle flux and much larger for the natural fluxes. Figure 3 shows the calculated flux from the combined rice and herbivores versus the ratio of the lifetime in 1978 to the lifetime in pre-industrial times for lifetimes of 8 and 10 years in 1978. If the emissions inventory estimates for the combined fluxes of rice and herbivores are correct, then the lifetime has been decreasing since pre-industrial times by as much as $33 \%$. The existing uncertainties for the lifetime as well as for the emissions inventory estimates of fluxes from rice and herbivores are the limiting factors in determining the natural fluxes, or the lifetime in pre-industrial times. There is other evidence that the 


\section{CALCULATED COMBINED FLUXES FROM RICE AND CATTLE}

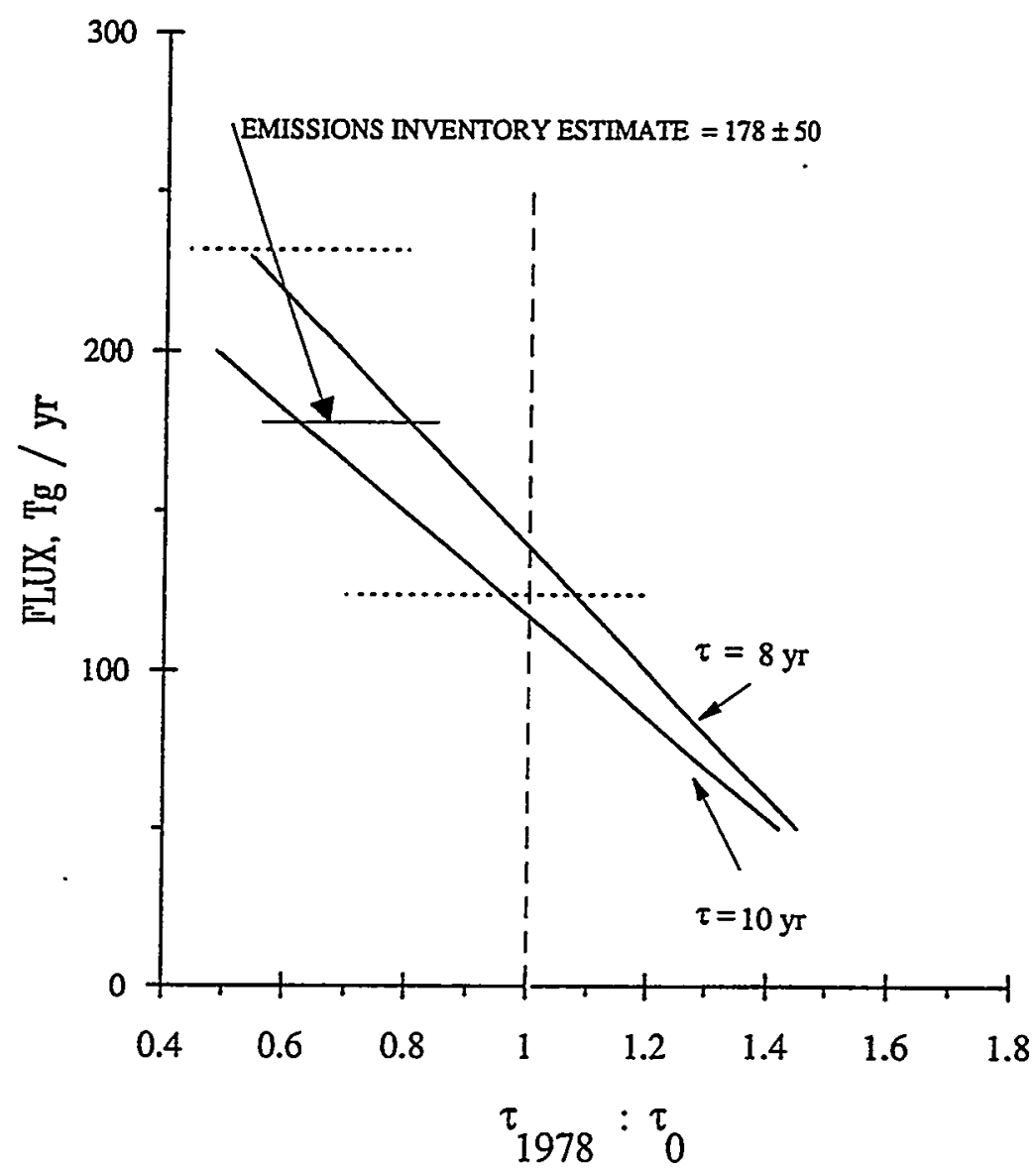

Figure 3. The calculated combined fluxes from rice and herbivores versus the ratio of the lifetime in 1978 to the lifetime in pre-industrial times for lifetimes of 8 and 10 years in 1978.

concentration of tropospheric ozone, the precursor of $\mathrm{OH}$ radicals that scavenge $\mathrm{CH}_{4}$, has been increasing in recent decades as well as in the past century (Logan, 1985; Hough and Derwent, 1990). In the following section on isotopic trends, other evidence is presented that shows that the sink rate in the northern hemisphere has been increasing in the past decade.

The flux from biomass burning that is calculated from the isotopic data in the above treatment falls in the narrow range of 37 to $50 \mathrm{Tg} / \mathrm{yr}$ if the flux from rice and herbivores is in the range of 110 to $178 \mathrm{Tg} / \mathrm{yr}$. This is illustrated in : Figure 4, which gives the fluxes from rice and herbivores versus the flux from biomass burning for a lifetime of ten years. A higher upper limit for the latter would seem unlikely since this would lead to unreasonably small fluxes for the natural sources. 
Table 5. The fluxes of the sources of atmospheric $\mathrm{CH}_{4}$ in 1978 , assuming a constant lifetime over the age of the ice cores in which the concentration and isotopic composition were measured and based on the flux from landfills of $50 \mathrm{Tg} / \mathrm{yr}$.

\begin{tabular}{lllll}
\hline & & \multicolumn{3}{c}{ Flux Tg/yr } \\
\cline { 3 - 5 } Source & $\begin{array}{l}\text { \% of } \\
\text { total }\end{array}$ & $\begin{array}{l}\text { 10-year } \\
\text { lifetime }\end{array}$ & $\begin{array}{l}\text { 8-year } \\
\text { lifetime }\end{array}$ & $\begin{array}{l}\text { Estimate by emissions } \\
\text { inventory }\end{array}$ \\
\hline Natural & 41 & $189(\mathrm{a})$ & $236(\mathrm{a})$ & $100(\mathrm{~b})$ \\
Rice + & & & 146 & $178 \pm 54(\mathrm{c})$ ranges \\
Herbivores & 24 & 110 & 146 & $50 \pm 20(\mathrm{~d})$ ranges \\
Landfills & 10.8 & 50 & 50 & $60(\mathrm{e})$ \\
Fossil Fuel & $17 \pm 3$ & 78 & 85 & 15 to $71(\mathrm{f})$ \\
Biomass Burning & 7.5 & 35 & 50 & \\
\hline
\end{tabular}

a. Lifetime assumed constant. b. Matthews and Fung, 1987. c. Schütz et al., 1989; Khalil and Rasmussen, 1991; Crutzen et al., 1986. d. Bingemer and Crutzen, 1987. e. Holzapfel-Pschorn and Seiler, 1986; Hitchcock and Wechsler, 1972. f. Crutzen and Andreae, 1990.

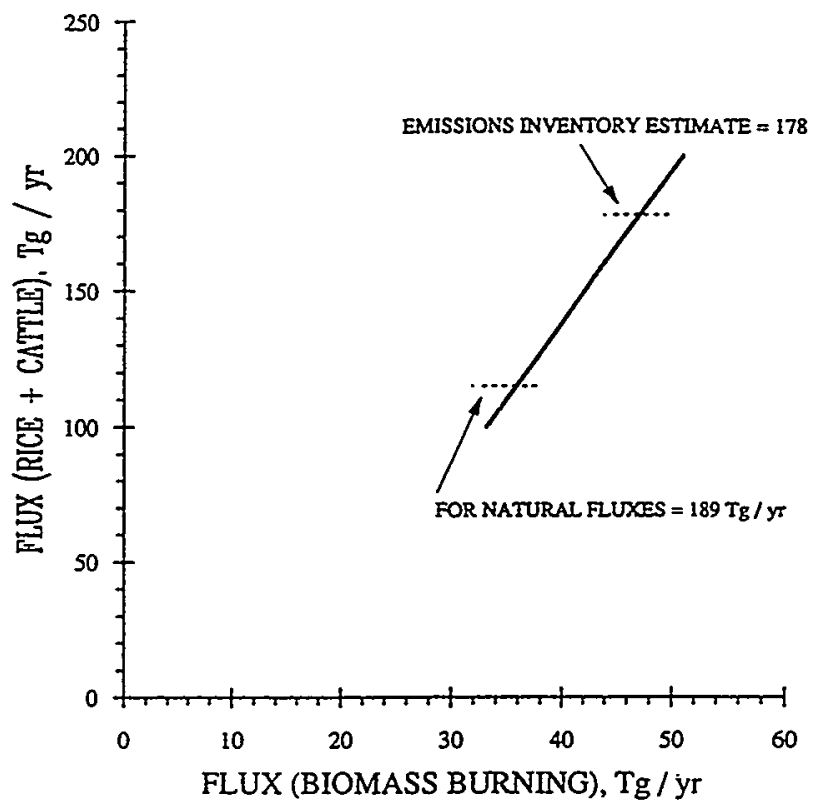

Figure 4. The calculated relationship between the combined fluxes from rice and herbivores and the fluxes from biomass burning for a lifetime of 10 years and the fluxes of the natural sources undetermined.

The isotopic abundance of deuterium in atmospheric $\mathrm{CH}_{4}$ and its sources provide an additional constraint for a global $\mathrm{CH}_{4}$ budget as shown by Wahlen et al. (1990). Their measurements show the global average $\delta \mathrm{D}$ for atmospheric $\mathrm{CH}_{4}$ is $-82 \%$, while $\delta \mathrm{D}$ for the biogenic $\mathrm{CH}_{4}$ from the major wet environments sources is -290 to $-360 \%$. The deuterium data provide additional constraints for calculating a budget of fluxes: first, the $\delta \mathrm{D}$ of the $\mathrm{CH}_{4}$ from wet environments correlates with the $\delta \mathrm{D}$ of the local precipitation, which is latitudedependent. This makes it possible to distinguish $\mathrm{CH}_{4}$ from tropical and arctic 
wetlands; secondly, the $\delta \mathrm{D}$ of fossil fuel $\mathrm{CH}_{4}$ has a different relative composition compared to the value for $\mathrm{CH}_{4}$ from wetlands than in the case for the carbon isotopes. The fractionation factor of $(\alpha-1)=-0.330$ measured by Gordon and Mulac (1975) for the oxidation of $\mathrm{CH}_{3} \mathrm{D} / \mathrm{CH}_{4}$ by $\mathrm{OH}$ radicals seems too large, leading to an average value for the sources more depleted than the value of the most depleted source. Wahlen et al. (1990) derives a value of -0.150 to -0.170 based on the enrichment of $\mathrm{CH}_{3} \mathrm{D}$ in the stratosphere where the concentration decreases with altitude because of $\mathrm{OH}$ oxidation.

\section{Temporal trends of the $\delta^{13} \mathrm{C}$ ratio in atmospheric methane}

The ice core data showed that the isotopic composition remained constant for 200 years while the concentration had increased from 0.65 to $1.2 \mathrm{ppm} 3$ to 5 decades ago (Craig et al., 1988). The $2 \%$ enrichment since then is attributed mainly to the heavy $\mathrm{CH}_{4}$ from biomass burning and fossil fuel sources that must be increasing more rapidly than the increase in light $\mathrm{CH}_{4}$ from rice and cattle.

Figure 5 shows the temporal trend of the carbon- 13 isotopic composition of atmospheric $\mathrm{CH}_{4}$ from 1978 to 1989 in both hemispheres. These plots are an update of earlier data reported by Stevens et al. (1985) and Stevens (1988). These data consist of analyses of 29 samples in the southern hemisphere (SH) and 129 in the northern hemisphere (NH), which are presented in this plot as annual averages. The slopes of these trends are greater by $0.04 \%$ \%olyr than shown in an earlier publication of the same data up to 1987 (Stevens, 1988) because of a correction factor applied to the results of analyses done in 1983 of samples collected as far back as 1978 and stored. The oldest of these samples from 1978 collections were analyzed again five years later in 1988 and showed a small increase of $\delta^{13} \mathrm{C}$ compared to the 1983 value, averaging $0.2 \%$, as well as slightly higher concentrations. The differences are interpreted as contamination with isotopically heavier $\mathrm{CH}_{4}$ from the walls of the storage cylinders accumulating over the 5-year interval between analyses, amounting to a correction of $-0.04 \%$ per year of the interval between collection and analysis of the stored air samples. This correction makes only a small change in the calculated trends of the isotopic composition of the sources in each hemisphere because the principal term in this calculation is the rate of change of the difference between the atmospheric $\delta^{13} \mathrm{C}$ trends, which is not altered by this correction (see equations 3 and 4 below). The correction increases the slopes of the trends in both hemispheres somewhat, but the difference between them remains the same.

The results in Table 4 and Figure 1 show that laboratory B measured a difference in the isotopic values between hemispheres of $0.7 \pm 0.3 \%$ in 1986-87 versus $0.5 \pm 0.2 \%$ for laboratory $A$ for the same years. The results of Lassey et al. (1993) (E) showed no change in the $\delta^{13} \mathrm{C}$ of the SH from late 1989 to late 1991 with much smaller uncertainties and many more analyses per year (40 to 50) than any other group. This does not necessarily conflict with the increasing trend observed by lab A since the two studies do not overlap, and it is possible that there could have been a change in the trend as happened after 1983 in the NH data of laboratory $\mathrm{A}$ in Figure 5. A decrease in the trend of $\delta^{13} \mathrm{C}$ in the SH 


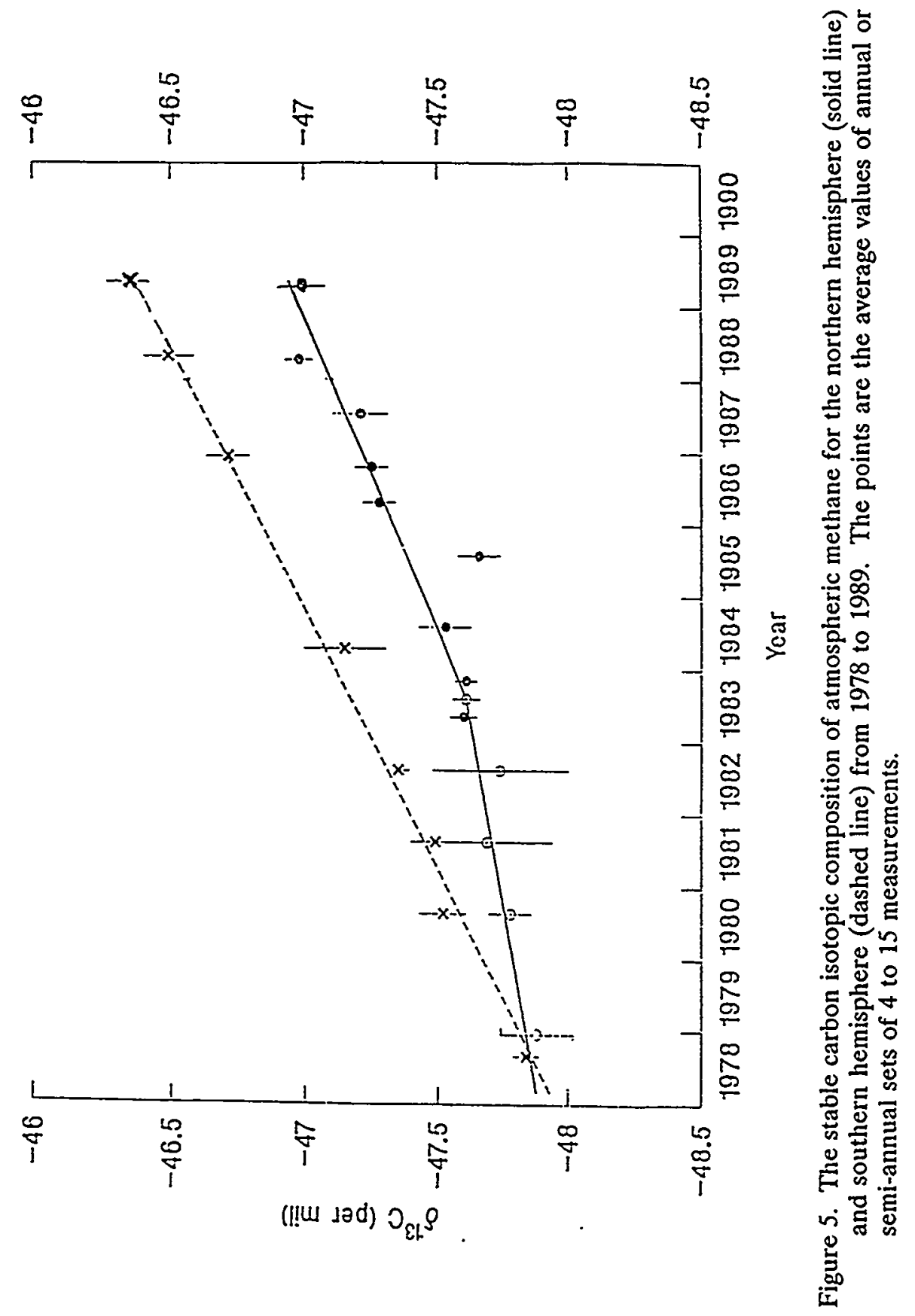

B-16 
would result if there was a significant reduction in biomass burning in the Amazon in recent years.

During the decade $1978-88$ the trend of $\delta^{13} \mathrm{C}$ for atmospheric $\mathrm{CH}_{4}$ was 0.14 \%o/yr in the SH and averaged $0.08 \%$ oolyr in the NH; there was a change in the slope in the $\mathrm{NH}$ after 1983 from $0.054 \pm 0.017$ to $0.112 \pm 0.008 \%$ \%/yr. The difference of $0.058 \pm 0.019 \%$ o/yr between these trends is more than three times the standard deviation.

The trends of the average isotopic composition of the source fluxes in each hemisphere can be derived using a two box model of the atmosphere, with the mass balance equations for ${ }^{13} \mathrm{CH}_{4}$ and ${ }^{12} \mathrm{CH}_{4}$ taking into account the interhemispheric exchange. They are

$$
\begin{aligned}
& \mathrm{d} \delta_{\mathrm{NS}} / \mathrm{dt}=\mathrm{d} \delta_{\mathrm{NA}} / \mathrm{dt}-\frac{\eta_{\mathrm{ex}}\left(\mathrm{C}_{\mathrm{S}} / \mathrm{C}_{\mathrm{N}}\right)\left[\mathrm{d}\left(\delta_{\mathrm{SA}}-\delta_{\mathrm{NA}}\right) / \mathrm{dt}\right]}{\left.\eta+\mathrm{dC} / \mathrm{Cdt}+\eta_{\mathrm{ex}} \mathrm{C}_{\mathrm{N}} / \mathrm{C}_{\mathrm{S}}-1\right]} \\
& \mathrm{d} \delta_{\mathrm{SS}} / \mathrm{dt}=\mathrm{d} \delta_{\mathrm{SA}} / \mathrm{dt}+\frac{\eta_{\mathrm{ex}}\left(\mathrm{C}_{\mathrm{N}} / \mathrm{C}_{\mathrm{S}}\right)\left[\mathrm{d}\left(\delta_{\mathrm{SA}}-\delta_{\mathrm{NA}}\right) / \mathrm{dt}\right]}{\eta+\mathrm{dC} / \mathrm{Cdt}-\eta_{\mathrm{ex}}\left[1-\mathrm{C}_{\mathrm{S}} / \mathrm{C}_{\mathrm{N}}\right]}
\end{aligned}
$$

where $\delta_{\mathrm{NA}}$ and $\delta_{\mathrm{SA}}$ are $\delta^{13} \mathrm{C}$ of atmospheric $\mathrm{CH}_{4}$ in the $\mathrm{NH}$ and $\mathrm{SH}$ respectively, $\delta_{\mathrm{SS}}$ and $\delta_{\mathrm{NS}}$ are $\delta^{13} \mathrm{C}$ of the average $\mathrm{CH}_{4}$ sources, and $\mathrm{C}_{\mathrm{N}}$ and $\mathrm{C}_{\mathrm{S}}$ are the concentrations in the respective hemispheres, $\eta$ and $\eta_{\mathrm{ex}}$ are the loss rate and interhemispheric exchange rate. The ${ }^{13} \mathrm{C}^{12} \mathrm{C}$ ratio of the sources in the $\mathrm{SH}$ increased at an average rate of $0.63 \%$ o/yr for the decade (Figure 6). In that hemisphere, biomass burning is the major anthropogenic source; rice and cattle production are estimated at only 20 and 25\%, respectively (Khalil and Rasmussen, 1983), of the global production, while losses from natural gas systems, coal mining, and landfills are negligible. The increasing trend can most plausibly be attributed to the increasing fluxes from the isotopically very heavy $\mathrm{CH}_{4}$ from biomass burning associated with the rapid deforestation in that hemisphere in recent decades. The magnitude of the isotopic trend gives a quantitative measure of the rate of increase of biomass burning in the southern hemisphere from the relationship

$$
\begin{aligned}
\mathrm{dF}_{\mathrm{BB}} / \mathrm{dt} & =\frac{\mathrm{F}_{\mathrm{S} . \mathrm{H} .}\left[\mathrm{d}\left(\delta_{\mathrm{S.H} .}\right) / \mathrm{dt}\right]}{\left(\delta_{\mathrm{BB}}-\delta_{\mathrm{AVG}}\right)} \\
& =3.5 \mathrm{Tg} / \mathrm{yr}^{2}
\end{aligned}
$$

where $F_{B B}$ is the flux from biomass burning in the southern hemisphere, $F_{\text {S.H. }}$ the total flux in the southern hemisphere of ca. $180 \mathrm{Tg} / \mathrm{yr}$, and $\delta_{\mathrm{BB}}$, the isotopic composition for $\mathrm{CH}_{4}$ from biomass burning, $-22 \%$. This rate would be 0.2 $\mathrm{Tg} / \mathrm{yr}^{2}$ greater taking into account the increasing rates ( 1 to $2 \% / \mathrm{yr}$ ) of the small fluxes of light $\mathrm{CH}_{4}$ from rice and cattle in this hemisphere. Since the increasing global concentration of atmospheric $\mathrm{CH}_{4}$ is $1 \%$ yr (Blake and Rowland, 1988; 


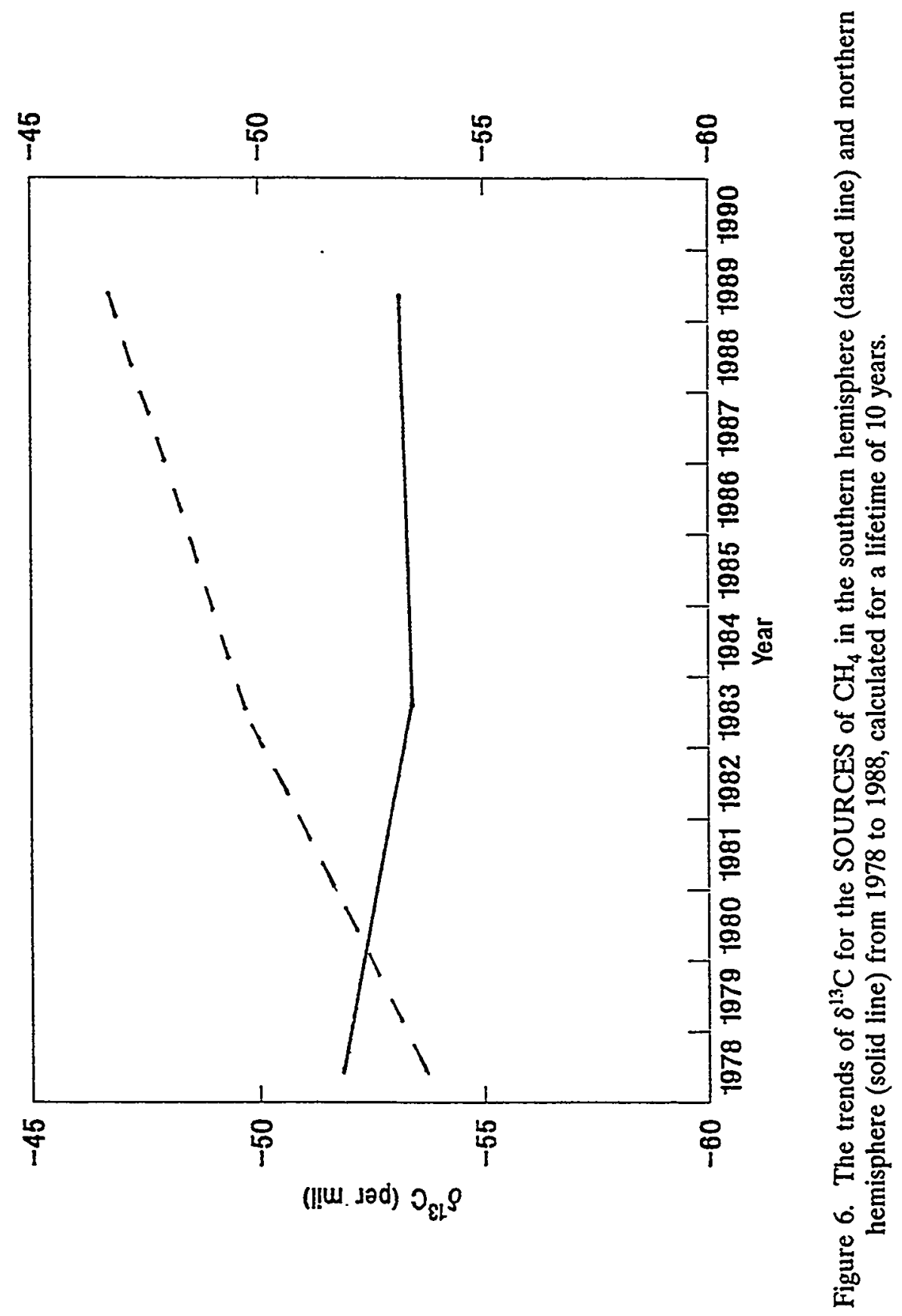

B-18 
Khalil and Rasmussen, 1990) and the global flux is about $500 \mathrm{Tg} / \mathrm{yr}$, the increasing fluxes from biomass burning in the southern hemisphere account for $50 \%$ of the increasing concentration and must be its leading cause, assuming the other $50 \%$ is due to increasing fluxes of all the anthropogenic sources in the northern hemisphere and the sink rate and fluxes of the natural sources are constant. Analysis of the trends in the northern hemisphere will show that both the fluxes of the natural sources and the loss rate are probably increasing; however, biomass burning in the southern hemisphere is the major anthropogenic source contributing to the increase in the concentration.

The trend of the $\delta^{13} \mathrm{C}$ of the sources in the northern hemisphere averaged $-0.17 \pm 0.03 \%$ o/yr over the decade. The slope was $-0.36 . \%$ o/yr until 1983 , when it changed to $+0.02 \%$ oolyr. Table 6 lists the calculated average rate of change for the decade based on estimates of the rates of growth of the isotopically light and heavy $\mathrm{CH}_{4}$ fluxes of the anthropogenic sources in this hemisphere as +0.02 to $+0.08 \%$ \% $/ y r$; the measured trend is significantly different by -0.19 to $-0.25 \%$ oo/yr. The disparity with the average measured trend is too large to be explained by uncertainties in the factors involved in the calculation, namely, rates of growth and fluxes. The difference implies that there was a much greater increase in the fluxes of isotopically light $\mathrm{CH}_{4}$ than can be reasonably accounted for by the increases in the production of rice and cattle, the only light anthropogenic sources. A plausible explanation is that the fluxes of the natural sources were changing (i.e., some combination of increasing light $\mathrm{CH}_{4}$ or decreasing heavy $\mathrm{CH}_{4}$ fluxes). The former possibility seems more likely because the temperate zone wetlands in the subarctic regions of the $\mathrm{NH}$ account for a major fraction of the global natural sources (Matthews and Fung, 1987) and produce light $\mathrm{CH}_{4}$ (Quay

Table 6. The calculated contribution of the increasing fluxes of the anthropogenic sources to the trend of the average isotopic composition of the sources for the northern hemisphere from 1978 to 1989 and comparison with the measured change.

\begin{tabular}{|c|c|c|c|c|}
\hline Source & $\begin{array}{l}\text { Flux } \\
(\mathrm{Tg} / \mathrm{yr})\end{array}$ & $\begin{array}{l}\text { Growth } \\
\text { Rate (\%/yr) }\end{array}$ & $\begin{array}{c}\left(\delta^{13} C_{i}-\delta^{13} C_{\text {avg }}\right) \\
(\% 00)\end{array}$ & $\begin{array}{c}\mathrm{d}\left(\delta^{13} \mathrm{C}\right) / \mathrm{dt} \\
(\% \circ / \mathrm{yr})\end{array}$ \\
\hline $\begin{array}{l}\text { Rice } \\
\text { Cattle } \\
\text { Landfills } \\
\text { Fossil Fuel } \\
\text { Biomass } \\
\text { Burning }\end{array}$ & $\begin{array}{l}80 \\
68 \\
50 \\
69 \\
20 \text { (b) }\end{array}$ & $\begin{array}{l}0.5 \text { to } 1.0 ? \\
0.6 \\
2.0 \text { (a) } \\
2.75 \\
0 \text { to } 2 \text { (a) }\end{array}$ & $\begin{array}{l}-12 \\
-8 \\
+2 \\
+12 \\
+22\end{array}$ & $\begin{array}{l}-0.016 \text { to } \\
-0.032 ? \\
-0.009 \\
+0.003 \\
+0.06 \\
+0 \text { to } 0.04\end{array}$ \\
\hline farcusated & 0 & $+0.08 \% 00 / y \mathrm{yr}$ & \multicolumn{2}{|c|}{ Measured rate $=-0.17 \%$ coly } \\
\hline
\end{tabular}

The indicated difference corresponds to 4 to $6 \mathrm{Tg} / \mathrm{yr}^{2}$ in the rate of increase of a flux of $\mathrm{CH}_{4}$ having $\delta^{13} \mathrm{C}=-65 \%$.

a. Assumed rate equals population growth.

b. Flux in the northern hemisphere assumed to be half of the lower limit of the range calculated for biomass burning shown in Figure 3, $40 \mathrm{Tg} / \mathrm{yr}$. 
et al., 1988). There was an increase in global temperature from 1975 to 1982 that could have caused increases in fluxes from these wetlands (Harriss, 1989), as well as increasing fluxes from rice paddies that were not accounted for by increasing acreage. The change in slope for the $\mathrm{NH}$ in 1983 coincides with a decrease in the slope of the global concentration trend after 1983 (Khalil and Rasmussen, 1990); thus, for the two phenomena to be caused by the same event would require a relatively rapid change over a few years of either a decrease of isotopically light fluxes or an increase in the loss rate. Based on the ratio of the change in slope of the isotopic trend to the change in slope of the concentration trend, the former possibility is more likely. This is further supported by the evidence of a pronounced cooling of $1^{\circ} \mathrm{C}$ during 1984-85 for the northern temperate zone (Angell, personal communication), which might have caused decreased fluxes from these northern wetlands and the change in the slope of the isotopic trend observed after 1983. The trend of the isotopic composition of atmospheric $\mathrm{CH}_{4}$ might be a simple indicator of average temperature trends in the regions of the northern temperate zone wetlands. There is evidence that the arctic regions have undergone amplified warming (Lachenbruch and Marshall, 1986), which is predicted in models of climate change. Continuous monitoring of the isotopic trends in both hemispheres over the coming decades might be a means of indicating these changes. The results of the trend data show increasing fluxes of biomass burning in the $\mathrm{SH}$ of $3.5 \mathrm{Tg} / \mathrm{yr}$ and increasing light $\mathrm{CH}_{4}$ fluxes in the $\mathrm{NH}$ of $4.2 \mathrm{Tg} / \mathrm{yr}$. Adding these to the increasing fluxes from the other anthropogenic sources from increasing production of rice $(1.0 \mathrm{Tg} / \mathrm{yr})$, cattle $(0.4$ $\mathrm{Tg} / \mathrm{yr}$ ), and fossil fuel $(1.7 \mathrm{Tg} / \mathrm{yr})$ gives a total of 10.8 to $15.1 \mathrm{Tg} / \mathrm{yr}$, or two to three times the total based on the increasing concentration of $1 \% / y r$ for an annual flux of $460 \mathrm{Tg} / \mathrm{yr}$ in 1978. From this it is deduced that the loss rate must be increasing by about 1 to $2 \% / y r$.

\section{Summary}

Carbon isotopic data have been used to elucidate three features of the atmospheric $\mathrm{CH}_{4}$ cycle: (1) the magnitude of the fluxes from the combined rice and cattle source and from biomass burning, (2) annual rates of change for the fluxes of biomass burning in the $\mathrm{SH}$ and natural wetlands in the $\mathrm{NH}$, and (3) indirect evidence of changes in the loss rate.

The sources of atmospheric $\mathrm{CH}_{4}$ have been divided into five categories (Table 5) based on a combination of similar isotopic composition or source characteristics. The fraction of the annual flux due to fossil fuel sources can be determined from carbon-14 measurements. The flux of the natural source is based on the concentration of $\mathrm{CH}_{4}$ in pre-industrial times as measured in polar ice cores with the caveat of possible changes in the lifetime. Taking the flux of the less important source of landfills based on emissions inventory data, then the carbon-13 data are limited to the determination of the ratio of the fluxes of the two remaining and isotopically different sources, namely those of heavy $\mathrm{CH}_{4}$ from biomass burning and light $\mathrm{CH}_{4}$ from the combined sources of rice paddies and 
ruminants. This ratio is subject to the possibility of changes in the lifetime (increasing loss rate) as shown in Figures 3 and 4.

The different isotopic trends for the two hemispheres are analyzed with the following conclusions: The isotopic composition of the overall sources in the southern hemisphere is becoming heavier and is most likely due to heavy $\mathrm{CH}_{4}$ from the only important anthropogenic source in this hemisphere, burning of biomass, which has been increasing rapidly in recent decades in this hemisphere. The northern hemisphere showed an increasing net depletion of ${ }^{13} \mathrm{CH}_{4}$ of the source $\mathrm{CH}_{4}$ during the past decade after taking account of increasing anthropogenic fluxes, as well as an abrupt increase of ${ }^{13} \mathrm{CH}_{4}$ in 1984-85. These changes are interpreted as caused by changing emissions of the isotopically light $\mathrm{CH}_{4}$ from the natural northern wetlands as well as rice paddies due to climate changes.

Finally, there are indications from both the budget calculations and trend results that the sink rate has been increasing. Because of these important findings, especially the possibility of the natural fluxes changing with climate change, there should be continuing measurements of the isotopic trends in both hemispheres. It would be best to have these analyses for both hemispheres done by the same laboratory using the same processing techniques and isotopic measurement standards in order to avoid the difficult calibration problems between different laboratories.

Acknowledgements. The preparation of the graphics was by Carter Lewis. Work performed under the auspices of the Interdisciplinary Research Program in Earth Sciences, National Aeronautics and Space Administration, Order No. W-16188, and the Office of Basic Energy Sciences, Division of Mathematical and Geosciences, U. S. Department of Energy, under Contract No. W-31-109-Eng-38, and the U.S. Environmental Protection Agency through Interagency Agreement, Reference No. DW 89934989-01-0.

\section{References}

Bingemer, H.G., P.J. Crutzen. 1987. The production of methane from solid wastes. J. Geophys. Res., 92:2,181-2,187.

Blake, D.R., F.S. Rowland. 1988. Continuing worldwide increase in tropospheric methane. Science, 239:1,129-1,131.

Burke, R.A., W.M. Sackett. 1986. Stable hydrogen and carbon isotopic compositions of biogenic methane from several shallow aquatic environments. In: Organic Marine Geochemistry (M.L. Sohn, ed.,) American Chemical Society, Washington, D.C., p. 297.

Cantrell, C.A., R.E. Shetter, A.H. McDaniel, J.G. Calvert, J.A. Davidson, D.C. Lowe, S.C. Tyler, R.J. Cicerone, J.P. Greenberg. 1990. Carbon kinetic isotope effect in the oxidation of methane by hydroxyl radicals. J. Geophys. Res., 95:22,455-22,462.

Chanton, J.P., C.S. Martens. 1988. Seasonal variations in ebullitive flux and carbon isotopic composition of methane in a tidal freshwater estuary. Global Biogeochem. Cycles, 2:289. 
Chanton, J.P., G.G. Pauly, C.S. Martens, N.E. Blair. 1988. Carbon isotopic composition of methane in Florida Everglades soils and fractionation during its transport to the troposphere. Global Biogeochem. Cycles, 2:245.

Cicerone, R.J., R.S. Oremland. 1988. Biogeochemical aspects of atmospheric methane. Global Biogeochemical Cycles, 2:299-327.

Craig, H. 1953. The geochemistry of the stable carbon isotopes. Geochim. Cosmochim. Acta, 3:53-92.

Craig, H., C.C. Chou. 1982. Methane: The record in polar ice cores. Geophys. Res. Lett., 9:1,212-1,224.

Craig, H., C.C. Chou, C.M. Stevens, A. Engelkemeir. 1988. Isotopic composition of methane in polar ice cores. Science, 242:1,535-1,539.

Crutzen, P.J., M.O. Andreae. 1990. Biomass burning in the tropics: Impact on atmospheric chemistry and biogeochemical cycles. Science, 250:1,669.

Crutzen, P.J., I. Aselmann, W. Seiler. 1986. Methane production by domestic animals, wild ruminants, other herbivorous fauna, and humans. Tellus, 38B:271-284.

Deines, P. 1980. The isotopic composition of reduced organic carbon. In: Handbook of Environmental Isotope Geochemistry, Vol. I (P. Fritz and J.C. Fontes, eds.), Elsevier Scientific, Chapter 9, p. 329-406.

Friedli, H., H. Lotscher, H. Oeschger, U. Siegenthaler, B. Stauffer. 1986. Ice core record of the ${ }^{13} \mathrm{C} /{ }^{12} \mathrm{C}$ ratio of Atmospheric $\mathrm{CO}_{2}$ in the past two centuries. Nature, 324:237.

Games, L.M., J.M. Hayes. 1976. On the mechanisms of $\mathrm{CO}_{2}$ and $\mathrm{CH}_{4}$ production in natural anaerobic environments. In: Proc. of the 2 nd International Conference on Environmental Biogeochemistry, Vol 1 (J.O. Nriague, ed.), Butterworth, Stoneham, Mass., p 51.

Gordon, S., W.A. Mulac. 1975. Reactions of the OH (X $\mathrm{X}^{2}$ II radical produced by the pulse radiolysis of water vapor. Int. J. Chem. Kinet., 7:289.

Harriss, R.C. 1989. Historical trends in atmospheric methane concentration and the temperature sensitivity of methane outgassing from boreal and polar regions. In: Proceedings of a Joint Symposium by the Board on Atmospheric Sciences and Climate and the Committee on Global Change Commission on Physical Sciences, Mathematics and Resources. National Academic Press, Washington D.C., p. 79.

Hitchcock, D.R., A.E. Wechsler. 1972. Biological cycling of atmospheric trace gases. Contr. Rep. NASA-CR 126663. Natl. Aeron. Space Adm., Washington D.C., p. 117.

Holzapfel-Pschorn, A., W. Seiler. 1986. Methane during a cultivation period from an Italian rice paddy. J. Geophy. Res., 91:11,803.

Hough, A., R.G. Derwent. 1990. Changes in the global concentration of tropospheric ozone due to human activities. Nature, 344:645.

Keeling, C.D., W.G. Mook, P.P. Tans. 1979. Recent trends in the ${ }^{13} \mathrm{C} /{ }^{12} \mathrm{C}$ ratio of atmospheric carbon dioxide. Nature, 277:121.

Khalil, M.A.K., R.A. Rasmussen. 1983. Sources, sinks, and seasonal cycles of atmospheric methane. J. Geophys. Res., 88:5,131-5,144.

Khalil, M.A.K., R.A. Rasmussen. 1990. Atmospheric methane: Recent global trends. Environ. Sci. Technol., 24:549.

Khalil, M.A.K., R.A. Rasmussen. 1991. Methane emissions from rice fields in China. Environ. Sci. Technol., 25:979.

Lachenbruch, A.H., B.V. Marshall. 1986. Changing climate: Geothermal evidence from permafrost in the Alaskan Arctic. Science, 234:689.

Lassey, K.R., D.C. Lowe, C.A.M. Brenninkmeijer, A.J. Gomez. 1993. Atmospheric methane and its carbon isotopes in the southern hemisphere: Their time series and an instructive model. Chemosphere, 26 (1-4):95-110. 
Levin, I., P. Bergamaschi, H. Dörr, D. Trapp. 1993. Stable isotopic signature of methane from different sources in western Europe. Chemosphere, 26 (1-4):161-178.

Logan, J.A. 1985. Tropospheric ozone: Seasonal behavior, trends and anthropogenic influence. J. Geophys. Res., 90:10,463.

Lowe, D.C., C.A.M. Brenninkmeijer, S.C. Tyler, E.J. Dlugokencky. 1991. Determination of the isotopic composition of atmospheric methane and its application in the antarctic. J. Geophys. Res., 96:15,455-15,467.

Matthews, E., I. Fung. 1987. Methane emissions from natural wetlands: Global distribution area, and environmental characteristics of sources. Global Biogeochem. Cycles, I:61.

Mayer, E.W., D.R. Blake, S.C. Tyler, Y. Makide, D.C. Montague, F.S. Rowland. 1982. Methane: interhemispheric concentration gradient and atmospheric residence time. Proc,. Natl. Acad. Sci, 79:1,366-1,370.

Oona, S., E.S. Deevey. 1960. Carbon 13 in lake waters and its possible bearing on paleolimnology. Am. J. Sci., 258A:253.

Ovsyannikov, V.M., V.S. Lebedev. 1967. Isotopic composition of carbon in gases of biogenic origin. Geochem. Int., 4:453.

Prinn, R., D. Cunnold, R.A. Rasmussen, P. Simmonds, F. Alyea, A. Crawford, P. Fraser, R. Rosen. 1987. Atmospheric trends in methylchloroform and the global average for the hydroxyl radical. Science, 238:945.

Quay, P., S.L. King, J.M. Lansdown, D.O. Wilbur. 1988. Isotopic composition of methane released from wetlands: Implications for the increase in atmospheric methane. Global Biogeochem. Cycles, 2:385.

Quay, P., S.L. King, J. Stutsman, D.O. Wilbur, L.P. Steele, I. Fung, R.H. Gammon, T.A. Brown, G.W. Farwell, P.M. Grootes, F.H. Schmidt. 1991. Carbon isotopic composition of atmospheric $\mathrm{CH}_{4}$ : fossil and biomass burning source strengths. Global Biogeochem. Cycles, 5:25.

Rice, D.D., G.E. Claypool. 1981. Generation, accumulation and resource potential of biogenic gas. Bull. Am. Assoc. Pet. Geol., 65:5.

Rust, F.E. 1981. Ruminant methane $\delta\left({ }^{13} \mathrm{C} /{ }^{12} \mathrm{C}\right)$ values: Relationship to atmospheric methane. Science, 211:1,044-1,046.

Schoell, M. 1980. The hydrogen and carbon isotopic composition of methane from natural gases of various origins. Geochem. Cosmochim. Acta, 44:649.

Schütz, H., A. Holzapfel-Pschorn, R. Conrad, H. Rennenberg, W. Seiler. 1989. A 3-year continuous record on the influence of daytime, season, and fertilizer treatment om methane emission rates from an Italian rice paddy. J. Geophys. Res., 94:16,405.

Stevens, C. 1988. Atmospheric methane. Chem Geol., 71:11.

Stevens, C., A. Engelkemeir. 1988. Stable carbon isotopic composition of methane from some natural and anthropogenic sources. J. Geophys Res., 93:725.

Stevens, C., A. Engelkemeir, R. Rasmussen. 1985. Causes of increasing methane fluxes based on carbon isotope studies. In: Special Environmental Report No. 16 (WMO-No.647); Lectures presented at the WMO Technical Conference on Observations and Measurement of Atmospheric Contaminants. World Meterol. Org., Geneva, Switzerland, p. 237.

Tyler, S.C. 1986. Stable carbon isotope ratios in atmospheric methane and some of its sources. J. Geophys. Res., 91:13,232.

Tyler, S.C., P.R. Zimmerman, C. Cumberbatch, J. Greenberg, C. Westberg, J.P.E.C. Darlington. 1988. Measurements and interpretation of $\delta 13 \mathrm{C}$ of methane from termites, rice paddies, and wetlands in Kenya. Global Biogeochem Cycles, 2:341.

United Nations Statistical Yearbook. 1988. 
Wahlen, M., N. Tanaka, R. Henry, B. Deck, Zeglan, J.S. Vogel, J. Southon, A. Shemesh, R. Fairbanks, W. Broecker. 1989. Carbon-14 in methane sources and in atmospheric methane: The contribution from fossil carbon. Science, 245:286.

Wahlen, M., N. Tanaka, B. Deck, R. Henry. 1990. $\delta \mathrm{D}$ in $\mathrm{CH}_{4}$ : Additional constraints for a global budget. EOS, 71 (43):1,249. 
ORNL/CDIAC-80

NDP-049

\section{INTERNAL DISTRIBUTION}

1. L. D. Bates

2. B. A. Berven

3. T. A. Boden

4. B. A. Berven

5. R B. Cook

6. J. H. Cushman

7. R. M. Cushman

8. V. H. Dale

9. N. T. Edwards

10. M. P. Farrell

11. D. E. Fowler

12. S. G. Hildebrand

13. G. K. Jacobs

14. S. B. Jones

15. P. Kanciruk

16. J. M. Loar

17. L. J. Morris

18. D. E. Reichle

19. R. J. Sepanski

20. F. E. Sharples

21. D. S. Shriner

22. L. D. Voorhees

23-222. CDIAC

223. Central Research Library

224-239. ESD Library

240-241. Laboratory Records Department

242. Laboratory Records, RC

243. ORNL Patent Section

244. ORNL Y-12 Technical Library

\section{EXTERNAL DISTRIBUTION}

245. D. Alvic, EERC/UT, Pellissippi Office, Ste. 100, 10521 Research Drive, Knoxville, TN 37932

246. Donald R. Blake, Department of Chemistry, University of California, Irvine, CA 92717

247. Roger C. Dahlman, Global Change Research Program, Environmental Sciences Division, Office of Health and Environmental Research, ER-74, U.S. Department of Energy, Washington, DC 20585 
249. Edward J. Dlugokencky, Carbon Cycle Division, National Oceanic and Atmospheric Administration, Climate Monitoring and Diagnostics Laboratory, 325 Broadway, Boulder, CO 80303-3328

250. R N. Farvolden, Professor, Department of Earth Sciences, University of Waterloo, Waterloo, Ontario N2L 3G1 Canada

251. Dr. Diana W. Freckman, Director, College of Natural Resources, 101 Natural Resources Building, Colorado State University, Fort Collins, CO 80523

252. Ian R Gross, Rishts and Permissions Administrator, Springer-Verlag New York, Inc., 175 Fifth Avenue, New York, NY 10010-7858

253. M.A.K. Khalil, Oregan Graduate Institute of Science and Technology, Global Change Research Center, P.O. Box 91000, Portland, OR 97291-1000

254. Ingeborg Levin, University of Heidelbert, Inst. fur Umweltphysik, Im Neuenheimer Feld 366, 6900 Heidelberg, Germany

255. Martin R. Manning, National Institute of Water and Atmospheric Research, Ltd., Climate Division, Gracefield Road, Gracefield, P.O. Box 31-311, Lower Hutt, New Zealand

256. Bobbi Parra, Global Change Research Program, Environmental Sciences Division, Office of Health and Environmental Research, ER-74, U.S. Department of Energy, Washington, DC 20585

257. Paul D. Quay, University of Washington, School of Oceanography, WB-10, Seattle, WA 98195

258. G. Y. Jordy, Director, Office of Program Analysis, Office of Energy Research, ER-30, G-226, U.S. Department of Energy, Washington, DC 20585

259. Ari Patrinos, Acting Director Office of Health and Environmental Research, ER-74, U.S. Department of Energy, Washington, DC 20585

260. R. A. Rasmussen, Oregon Graduate Institute of Science and Technology, Global Change Research Center, P.O. Box 91000, Portland, OR 97291-1000

261. Michael R. Riches, Acting Director, Environmental Sciences Division, Office of Health and Environmental Research, ER-74, U.S. Department of Energy, Washington, DC 20585

262. G. S. Sayler, Professor, 10515 Research Drive, Suite 100, The University of Tennessee, Knoxville, TN 37932-2567

263. L. Paul Steele, Commonwealth Scientific and Industrial Research Organization, Division of Atmospheric Research, Private Bat No. 1, Mordialloc, Victoria 3195, Australia

264-268. Charles M. Stevens, Analytical Chemistry Laboratory, Chemical Technology Division, Argonne National Laboratory, 9700 South Cass Avenue, Argonne, IL 60439-4831 
269. Pieter P. Tans, Carbon Cycle Division, National Oceanic and Atmospheric Administration, Climate Monitoring and Diagnostics Laboratory, 325 Broadway, Boulder, CO 80303-3328

270. Martin Wahlen, Scripps Institute of Oceanography, University of California, La Jolla, CA 92093-0220

271. F. J. Wobber, Environmental Sciences Division, Office of Health and Environmental Research, Office of Energy Research, ER-74, U.S. Department of Energy, Washington, DC 20585

272. Douglas E. J. Worthy, Environment Canada, Atmospheric Environment Service, 4905 Dufferin Street, Downsview, Ontario M3H 5T4, Canada

273. Office of Assistant Manager for Energy Research and Development, U.S. Department of Energy Oak Ridge Operations, P. O. Box 2001, Oak Ridge, TN 37831-8600

274-275. Office of Scientific and Technical Information, P. O. Box 62, Oak Ridge, TN 37831 